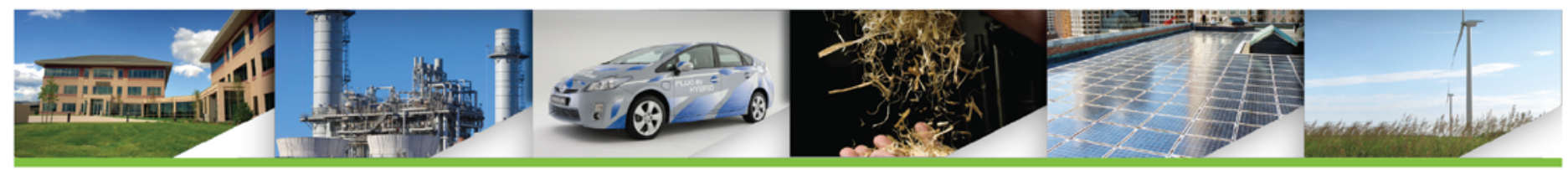

\title{
Integrating Clean Energy in Mining Operations: Opportunities, Challenges, and Enabling Approaches
}

Tsisilile Igogo, Travis Lowder, and Jill Engel-Cox National Renewable Energy Laboratory

Alexandra Newman

Colorado School of Mines

Kwame Awuah-Offei

Missouri University of Science and Technology

Technical Report

NREL/TP-6A50-76156

July 2020

Contract No. DE-AC36-0808GO28308 


\section{Integrating Clean Energy in Mining Operations: Opportunities, Challenges, and Enabling Approaches}

Tsisilile Igogo, Travis Lowder, and Jill Engel-Cox National Renewable Energy Laboratory

Alexandra Newman

Colorado School of Mines

Kwame Awuah-Offei

Missouri University of Science and Technology

The Joint Institute for Strategic Energy Analysis is operated by the Alliance for Sustainable Energy, LLC, on behalf of the U.S. Department of Energy's National Renewable Energy Laboratory, the University of Colorado-Boulder, the Colorado School of Mines, the Colorado State University, the Massachusetts Institute of Technology, and Stanford University.

The Joint Institute for Strategic Energy Analysis 1617 Cole Boulevard Golden, Colorado 80401 303-275-3000 • www.jisea.org

\section{Technical Report}

NREL/TP-6A50-76156

July 2020

Contract No. DE-AC36-08GO28308 


\section{NOTICE}

This work was authored in part by the National Renewable Energy Laboratory, operated by Alliance for Sustainable Energy, LLC, for the U.S. Department of Energy (DOE) under Contract No. DEAC36-08GO28308. Funding provided by the Joint Institute for Strategic Energy Analysis. The views expressed herein do not necessarily represent the views of the DOE or the U.S. Government.

This report is available at no cost from the National

Renewable Energy Laboratory (NREL) at

www.nrel.gov/publications.

U.S. Department of Energy (DOE) reports produced

after 1991 and a growing number of pre-1991

documents are available

free via www.OSTI.gov.

Cover Photos: (left to right) NREL 04135, iStock 22779761, NREL 16933., NREL 15648, NREL 08466, NREL 21205

NREL prints on paper that contains recycled content. 


\section{Acknowledgments}

We would like to thank all the participants of the November 7, 2019, scoping workshop on renewable integration in mining operations hosted by the Joint Institute for Strategic Energy Analysis Institute at the National Renewable Laboratory (NREL). Also, special thanks to Mark Ruth, James McCall, Parthiv Kurup, and Ian Baring-Gould for their valuable input and comments that helped improve this report. 


\section{List of Acronyms}

ARENA

$\mathrm{BF}$

BHB

BNEF

BOF

BTU

CAPEX

CHP

$\mathrm{CO}_{2}$

$\mathrm{CO}_{2 \mathrm{e}}$

$\mathrm{CSM}$

CSP

DPM

DRI

EIA

GDP

GER

GHG

GWh

HFO

HVAC

ICMM

IEA

IPP

IRENA

JISEA

$\mathrm{kWh}$

LCOE

$\mathrm{Mt}$

MW

NREL

OPEX

PPA

PV

R\&D

S\&T

SDG

TWh
Australia Renewable Energy Agency

blast furnace

Broken Hill Proprietary

Bloomberg New Energy Finance

blast oxygen furnace

British thermal unit

capital expenditure

combined heat and power

carbon dioxide

carbon dioxide equivalent

Colorado School of Mines

concentrating solar power

diesel particulate matter

direct reduced iron

U.S. Energy Information Administration

gross domestic product

gross energy requirement

greenhouse gas emission

gigawatt hours

heavy fuel oil

heating, ventilating, and air conditioning

International Council on Mining and Metals

International Energy Agency

independent power producer

International Renewable Energy Agency

Joint Institute for Strategic Energy Analysis

kilowatt-hour

levelized cost of energy

metric tons

megawatt

National Renewable Energy Laboratory

operation expenditure

power purchase agreement

photovoltaics

research and development

Missouri University of Science and Technology

sustainable development goal

terawatt-hour 


\section{Executive Summary}

Mining is one of the most energy-intensive industries worldwide. It is also a major source of raw materials for manufacturing, transportation, construction, and energy sectors. Demand for raw materials is projected to increase as the world population grows and many low-income economies become middle income countries. This growth in mineral demand, coupled with falling mineral ore grade, will likely increase the mining industry's energy demand.

Due to their remoteness, most mine operations are heavily dependent on fossil fuels such as diesel, heavy oil fuels, and coal, for on-site generation. In principle, mining could use many clean energy solutions such as energy efficiency, energy recovery, renewable energy, and carbon capture. A combination of clean energy technologies would be required to fully address energyrelated challenges facing the mining industry.

In this report, we explore challenges, opportunities, and enabling approaches to integrate renewable energy technologies into mining operations. The mining industry, as defined herein, spans activities across exploration, extraction, beneficiation and processing, and refining. This report was developed by a team of energy experts from the National Renewable Energy Laboratory (NREL) in collaboration with experts in mining engineering design and operations from the Colorado School of Mines (CSM) and Missouri University of Science and Technology (S\&T). This report was prepared using literature, analysis and discussions with key mining stakeholders from the workshop hosted at NREL on November 7, 2019, and with follow-up discussions with individual stakeholders. Below, we provide a summary of this report.

Trends and challenges shaping the mining industry: Based on input from the mining industry stakeholders and extensive research, at the time of this writing, the main trends and challenges shaping the mining industry and driving interest in renewable energy use in mining operations are:

1. Declining ore grade: The depletion of high-grade and easily accessible ores has led to declining ore grade; thus, more materials need to be extracted, loaded, hauled, transported, and processed, requiring more energy and, correspondingly, new investments in energy services.

2. Volatile Prices: The mining industry continually faces energy and mineral price fluctuations, which affect their cost of production; thus, renewables could offer consistency in costs of energy.

3. Increasing Environmental Concerns: The mining industry has been under increasing pressure to reduce environmental impacts generated by its activities such as material extraction and processing.

4. Increasing Political and Social Concerns: The mining industry is increasingly experiencing pressure from its shareholders and external stakeholders, including international organizations, host governments, local communities, and end-use product producers (metal buyers and their customers along the supply chain) to reduce dependence on fossil fuels and improve their environmental and social performance in the places where they operate. 
Renewable Integration Opportunities: Renewable integration opportunities can address some of the main challenges the mining industry is facing. These fall into two main categories:

1. Opportunities for Mining Operations: Several activities in the mining industry rely on electric power, and, thus, may be powered by renewable energy sources. Also, there are operations that use fossil fuel as source of energy that can benefit from electrification by renewable sources as follows:

A. Renewables for Electricity Demand: replacement of source of electricity used in mining operations with renewable energy sources

B. Renewables to Replace Fossil Fuel-Fired Loads: replacement of diesel-fired activities with renewable electricity through electrification

C. Renewables for Feedstock Demand: substitution of fossil fuel feedstocks with renewable feedstocks such as biomass and hydrogen

D. Production of Hydrogen: use of excess electricity from variable renewable energy to produce hydrogen that could be stored and used in other mining activities for electricity, transport, and heating.

2. Opportunities for Mining Communities and Circular Economy: In many resourcerich countries, mining towns are located in areas that lack access to reliable energy. Renewable technologies could be used to supply energy to these mining communities, creating jobs that leave lasting impact such as agribusiness enhancing political stability. But also, the use of renewables in mining is circular, as renewable technologies need minerals as key inputs. Creating stable mining economies and "greening" mining activities help reduce supply risks for renewable raw minerals such as cobalt.

Technical Considerations for Renewable Integration in Mining Operations: Existing limitations in the mining operations require consideration and further research to improve the viability of renewable energy, including:

1. Feedstock Demand: Some mining operations use fossil fuels as feedstock and for energy. The feedstock demand cannot be easily replaced with current renewable technologies.

2. Process Heat Demand: Certain activities require high-temperature heat. Many lowtemperature heat requirements can be met by a variety of clean energy sources while only a select few clean energy sources can meet the requirements of high-temperature heat.

3. Constant Energy Demand: Most mines operate on a largely uninterrupted schedule, requiring continuous energy supply for consistent 24/7 load requirements. However, some key renewables such as wind and solar energy generation are variable, and storage technologies cannot yet economically the support longer hours of storage required to cover off-peak mining operations. This limits the capacity of renewables that can be integrated into mining operations. 
4. Mining Industry Design and Investment Structure: The structure of mining investments makes it harder to phase out old technology and incorporate new technologies such as renewable energy or electrified equipment before end-of-mine-life. Clean energy sources need to be an integral part of mine planning and design during the planning phase, as well as during operation expansions.

Other Challenges for Renewable Integration in Mining Operations: Adoption of renewable energy for mining operations has been slow in spite of the potential that renewable energy sources present to the mining industry. Key challenges identified from conversations with mining stakeholders include:

1. Conflicting Business Models: Misalignment in commercial structure between the mining and energy industries make negotiating cost-effective renewable contracts difficult. For example, 20-year power purchase agreements - the predominant contracting mechanism used by renewable energy developers - are not well aligned with the year-toyear variable energy demand for off-grid mine operations.

2. Need for Technology Proofs of Concept: Limited commercial history of most renewable technologies for industrial processes affects small-to-medium size mining companies. Large mining companies have funds to run pilot studies to demonstrate renewable technologies before scaling to other operations.

3. Lack of Renewable Energy Awareness and Expertise: Decision makers at both the company and government levels do not often consider renewable solutions during mining project planning, negotiations, and design because of a lack of knowledge and tools to enable consideration of renewable sources.

4. Land Constraints: It is believed that mining companies generally own large tracts of land that could be viable for renewable energy installation such as solar photovoltaics and concentrating solar power, but such land is often located in terrain unsuitable (e.g., too steep or unstable) for installing most renewable systems.

Enabling Approaches: Regardless of the technical and nontechnical challenges, solutions can be employed to enable adoption of renewables in the mining industry, including:

1. Alignment of Business Model and Incentives: Developing business models and incentives can ensure mining flexibility and the energy industry assurance of return on investment.

2. Capacity Building: Knowledge in the form of improved tools and education programs could be used as means of addressing this knowledge gap.

3. Research and Development: R\&D could help address existing technical challenges in both renewable energy and mining industries that hinder applicability and scaling of several renewable sources.

4. Supply Chain Certifications: Certification efforts for green sources of minerals along the supply chain will help create the needed product differentiation, which may be appealing for downstream companies that are under pressure from their shareholders to source their inputs from sustainable sources. 
5. Pooling of Resources: Individual mines or groups of mines near communities without access to grid connections could collaborate to build a larger system as part of a microgrid or they could acquire the service from independent power producers and developers, thus creating the economies of scale needed to support larger systems.

6. Government Policies and Regulations: Though there are macro-level drivers, policies on implementation of renewable integration are still unclear in many countries where mining occurs. Only lately have some mineral-rich countries started to revise their policies to enable clean energy development for energy-intensive industries such as mining. 


\section{Table of Contents}

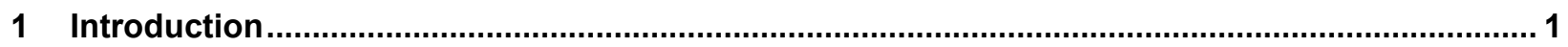

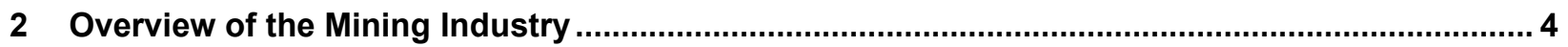

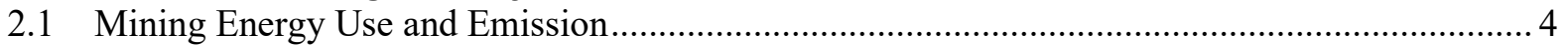

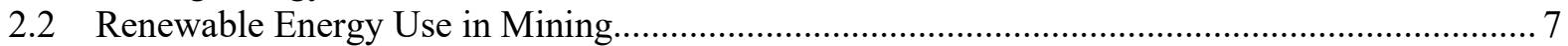

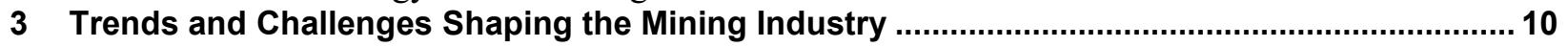

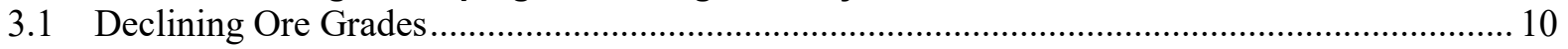

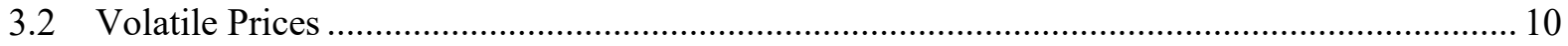

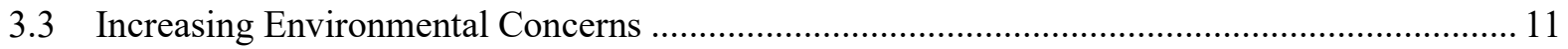

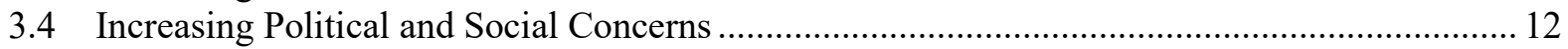

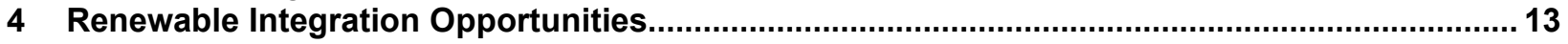

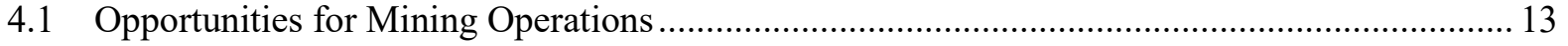

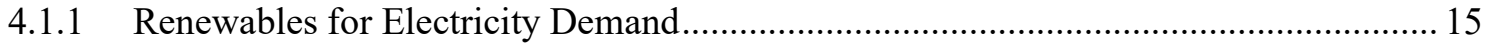

4.1.2 Renewables to Replace Fossil-Fueled Heat and Transportation ................................. 16

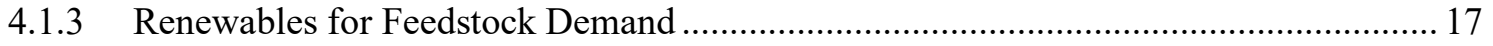

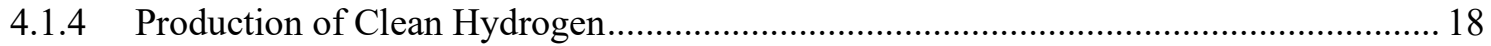

4.2 Opportunities for Mining Communities and the Circular Economy ....................................... 18

5 Technical Considerations for Renewable Integration in Mining Operations ............................ 20

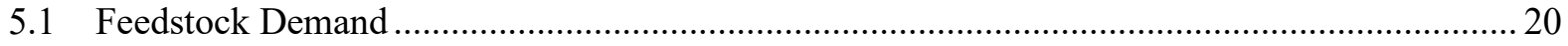

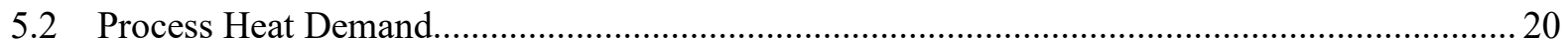

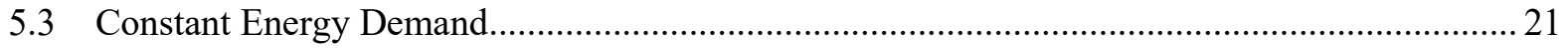

5.4 Mining Industry Design and Investment Structure ................................................................. 22

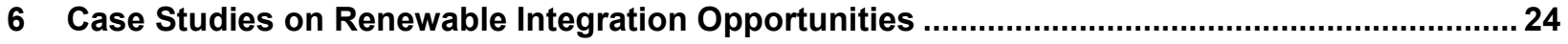

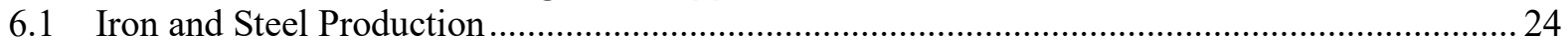

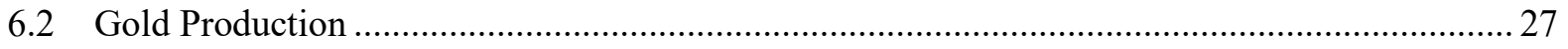

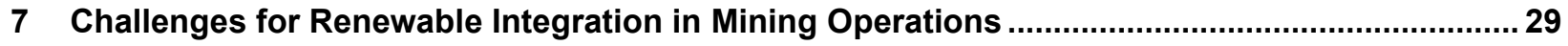

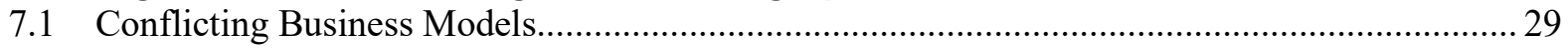

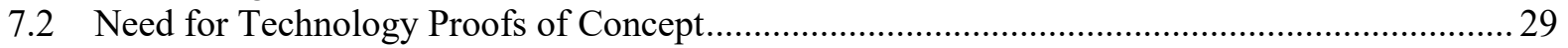

7.3 Lack of Renewable Energy Awareness and Expertise ............................................................. 30

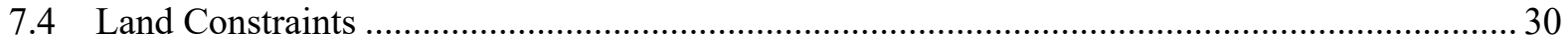

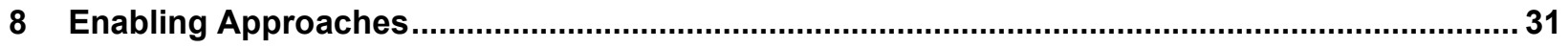

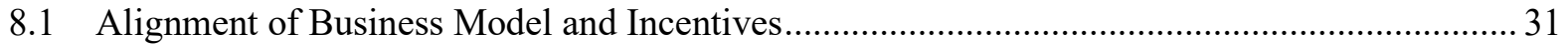

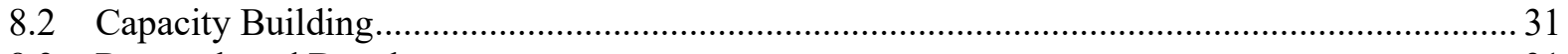

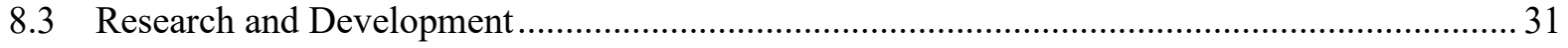

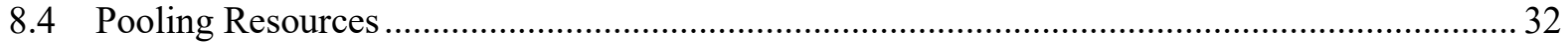

8.5 Government Policies and Regulations ……..................................................................... 32

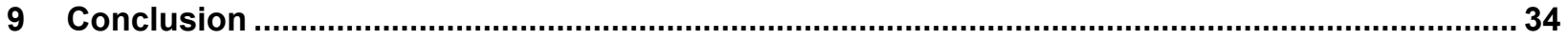

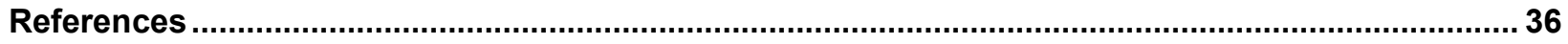

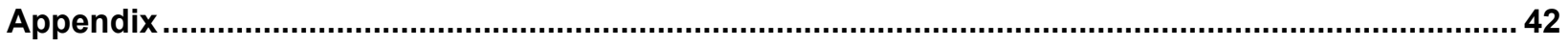

ix 


\section{List of Figures}

Figure 1. Energy consumption of select mineral production in sub-Saharan Africa ................................. 2

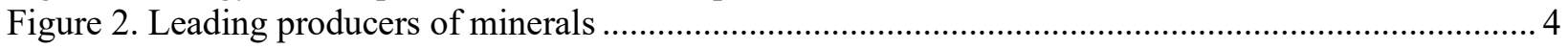

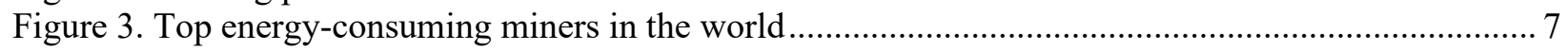

Figure 4. Renewable projects associated with mining companies worldwide ......................................... 8

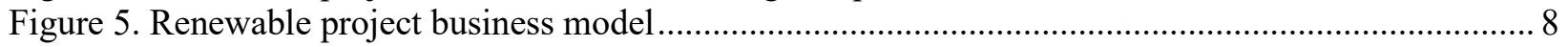

Figure 6. Renewable projects associated with mining companies worldwide...................................... 9

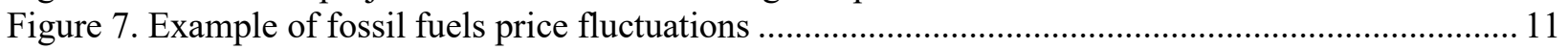

Figure 8. Primary metal production energy use in the United States................................................... 14

Figure 9. Nonmetallic mineral production energy use in the United States ......................................... 15

Figure 10. Total U.S. net electricity generation energy sources for all sectors, 2018............................. 16

Figure 11. Alumina and aluminum production energy use in the United States, YYYY ........................ 17

Figure 12. Worldwide mining activities and political stability status................................................... 19

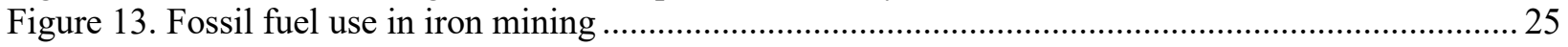

Figure 14. Iron and steel production energy use in the United States................................................... 26

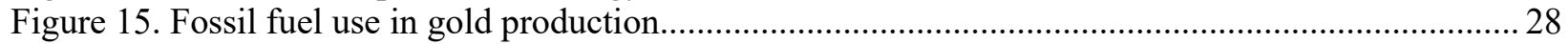

\section{List of Figures}

Table 1. Cradle-to-Gate Energy Use and GHG Impacts of Select Metals ............................................... 5

Table 2. Example of Mining Processes and Associated Fuel Sources................................................. 13

Table 3. Commercially Available and Economical Renewable Energy Technologies............................ 21

Table 4. Disaggregated Electricity Loads by Iron Ore Mining........................................................... 24

Table 5. Example of Disaggregated electricity Loads by the Gold Production........................................ 27 


\section{Introduction}

The mining industry is a major source of raw materials for many industries such as manufacturing, transportation, construction, energy, and the mining industry itself. It is anticipated that demand for raw materials is only going to increase as population grows and many low-income economies shift to middle-income status (MIT n.d.). The increase in mineral demand, combined with declining mineral ore grades, is expected to increase the energy demands of the mining industry, which will potentially expand its already large greenhouse gas (GHG) footprint (Norgate and Haque 2010; Lezak, Cannon, and Koch 2019). In principle, mining could use many clean energy solutions such as energy efficiency, energy recovery, renewable energy, and carbon capture to lower its energy consumption and decrease GHG emissions. A combination of clean energy technologies will be required to fully address energy related challenges facing the mining industry. This report explores the challenges, opportunities, and enabling approaches to integrate renewable technologies into mining operations.

Partly to combat its potentially expanding GHG profile, the mining industry is increasingly adopting renewable energy to power its operations. This uptick in adoption has been driven by several factors, including energy costs, corporate environmental goals, and social license to operate considerations. In 2015, there were $600 \mathrm{MW}$ of renewable energy projects sited on or serving mine sites. By the end of 2019, nearly $5 \mathrm{GW}$ of renewable energy projects were installed or planned for mine sites around the world (Kirk and Cannon 2020). This growth, however, has not been without headwinds. Integration of variable renewable energies with 24/7 mining operational loads, the distinctive nature of mining processing energy demand, inflexible contracting structures, space constraints on the mine site, policy and regulatory barriers, and others have inhibited adoption at scale.

This report uses the term "mining industry" to encompass activities covered under exploration, extraction, beneficiation, processing, and refining. The report was developed by a team of energy experts from the National Renewable Energy Laboratory (NREL) in collaboration with experts in mining engineering design and operations from the Colorado School of Mines CSM) and the Missouri University of Science and Technology (S\&T). The information included herein has been assembled from a thorough literature review, as well as through engagement with mining industry stakeholders.

Mining operations can be divided into two main energy-use categories: grid-connected operations and off-grid operations. Traditionally, most off-grid mining operations depend heavily on fossil fuels such as diesel, heavy oil fuels (HFOs), and coal for onsite generation and haulage (See example, Figure 1). However, as Figure 1 illustrates, grid-connected mining operations are also reliant on fossil fuels, to some degree. 

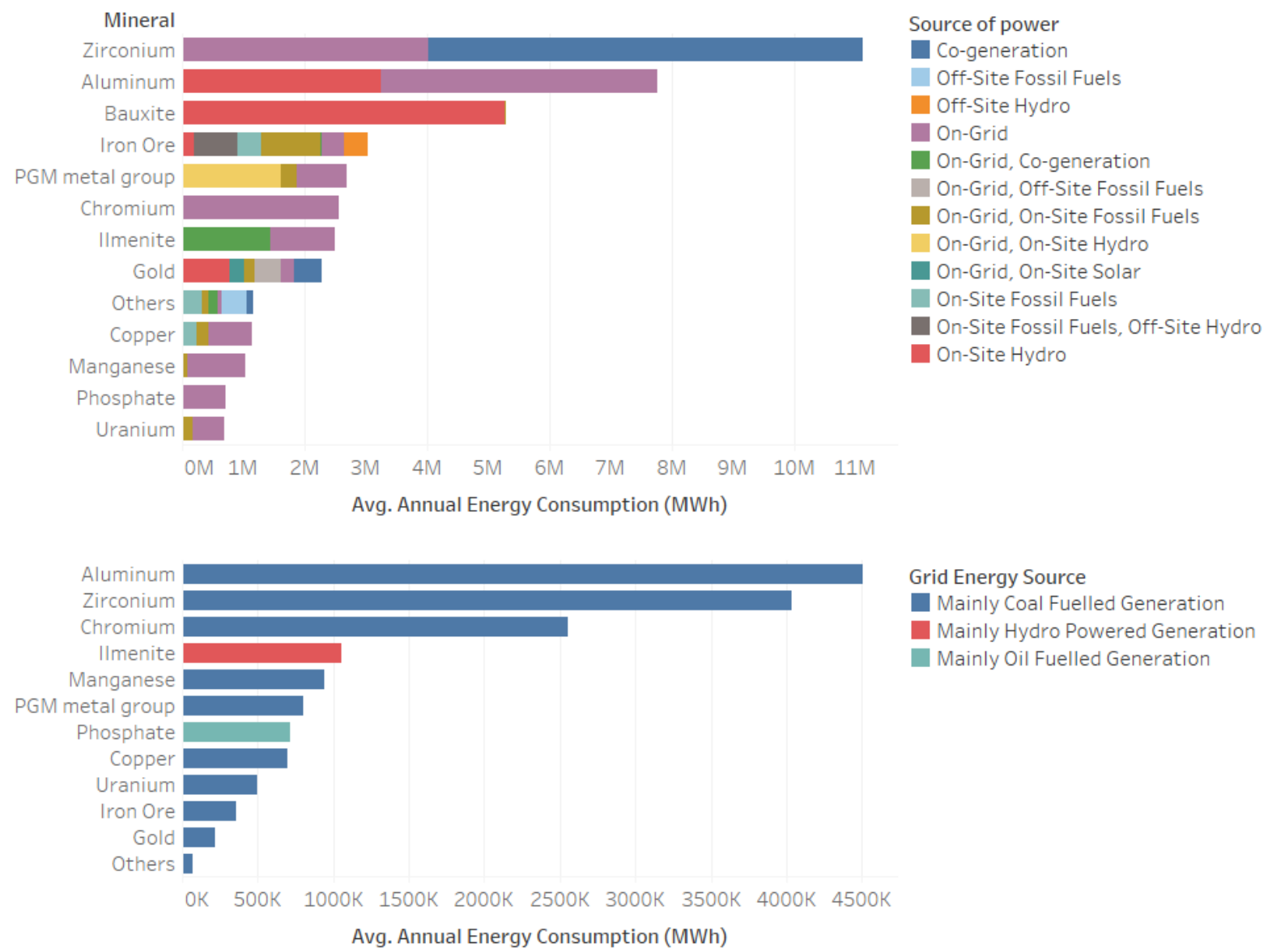

Figure 1. Energy consumption of select mineral production in sub-Saharan Africa

Data source: World Bank 2014

The top chart shows average annual energy consumption by on-grid and off-grid mineral production operations. The lower chart shows energy sources for operations that solely depend on grid-connected electricity. On-grid energy for these operations consist of mostly fossil fuels. Some on-grid operations have on-site or off-site power sources as backup or to supplement grid electricity. Some operations that rely on on-site energy sources sell excess to the grid, while some are not grid-connected thus cannot sell their excess to the grid. Power purchasing agreements vary across these mines, including operations that invest in the grid, self-supply and sell to the grid, and those that act as anchor customers for independent power producers.

The grid, where available, often provides the least costly source of energy for mining operations, and, as such, is typically preferred by the mining industry over self-generation. In many countries with unreliable grid supply, most grid-connected operations have additional on-site generation as backup. These are mostly sourced from fossil fuels, which adds to the cost of production.

Energy is one of the most significant expenses for the mining industry, comprising some $15 \%$ $40 \%$ of total operating costs, on average (Maennling Toledano 2018). With such a large proportion of expenditures devoted to energy production, and such a significant portion of that energy sourced from fossil fuels, the mining industry is highly exposed to fossil fuel market volatility. By one estimate, energy demand in mining operations is anticipated to grow by $36 \%$ by 2035 (Maennling Toledano 2018). 
Aside from the economic implications, the dependence on fossil fuels for mining also impacts the well-being of local communities and has implications for local infrastructure, air and water quality, and the environment. Moreover, pressure is increasing from further down the value chain, where purchasers of raw metals are beginning to require that their suppliers demonstrate sustainability in operations. All of these factors-economic, societal, and environmental - are motivating a reconsideration of how energy is generated and used at mining sites.

This report proposes that renewable energy integration into mining operations can address these pressures. ${ }^{1}$ Decreasing costs in wind, solar, geothermal, storage, and other renewable technologies are driving adoption worldwide (Larsen 2019). A growing renewables market, in turn, means higher demand for minerals and metals (including iron, nickel, lithium, platinum, and cobalt), which benefits mining companies and can create circular economies between the two industries.

The rest of the report is organized as follows: Section 2 presents an overview of the mining industry; Section 3 covers current trends and challenges shaping the mining industry; Section 4 discusses renewable integration opportunities; Section 5 highlights technical considerations for renewable integration in mining operations; Section 6 presents case studies on renewable integration opportunities; Section 7 lists challenges for renewable integration in mining operations; Section 8 offers enabling approaches; and Section 9 concludes the report.

${ }^{1}$ The authors recognize that, for mining operations that solely depend on on-grid power supply, efforts to increase renewable use will require cooperation of utility providers as mining operators do not have much control over their energy sources. In this case, solutions geared toward greening the grid system will be more appropriate-this is out of the scope of this report. But, even for on-grid operations, they require process energy (such as heat, machine drive, feedstocks) and non-process energy (such as ventilation), which is typically supplied by fossil fuels and could benefit from renewables. 


\section{Overview of the Mining Industry}

Mining and quarrying materials can be divided into four main groups: industrial minerals, metal minerals, aggregates, and mineral fuels. This report will focus on the first three categories, excluding mineral fuels as they have been addressed in other NREL research (see, for example, Ericson, Engel-Cox, and Arent 2019). Figure 2 ranks the largest producers of minerals in the world and categorizes their production into subgroups. ${ }^{2}$ Note the particularly high volume of iron and ferro-alloy metals - which include steel and stainless steel - produced worldwide. The energy requirements associated with extraction of iron ore as well as the production of steel products represents a sizable opportunity for renewables to play a role in decarbonization (see the appendix for a breakdown of the mineral types).

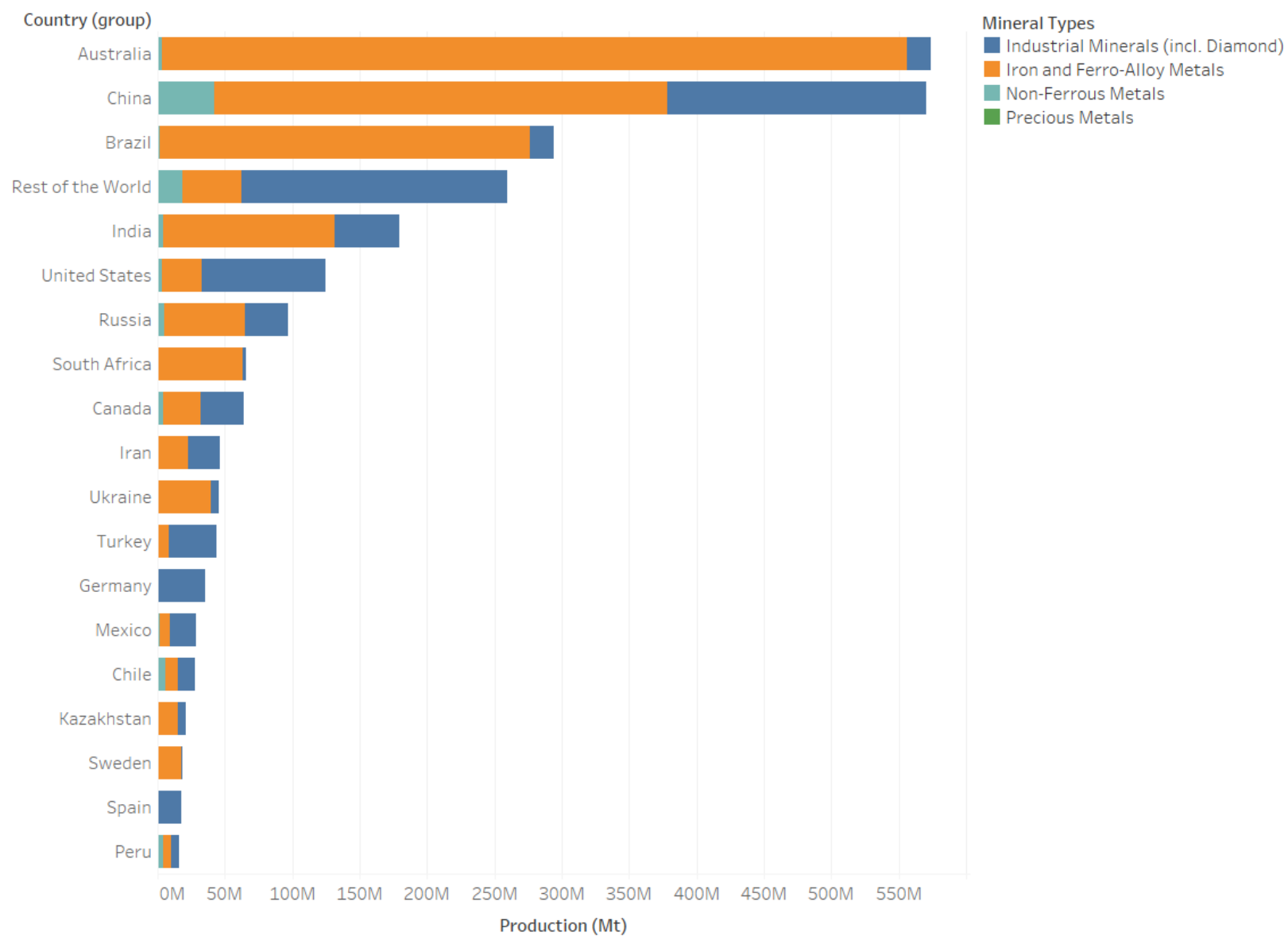

Figure 2. Leading producers of minerals

Data source: World Mining Data (n.d.)

\subsection{Mining Energy Use and Emission}

Generally, mining includes ground fragmentation (including drilling and blasting), excavation, loading, transportation, beneficiation, and processing, and smelting and refining. These operations make the mining industry one of the most energy intensive businesses, consuming

\footnotetext{
${ }^{2}$ Reliable data sources of global production for aggregates are not available.
} 
about $38 \%$ of total global industrial energy use, $15 \%$ of the total global electricity use, and $11 \%$ of total global energy use. The total global energy use by the mining industry comprises about $19 \%$ of global coal and coal products and $5 \%$ of global gas and $2 \%$ of global oil supplied (McLellan 2012). Total energy demand for mining is anticipated to grow over the near- to midterm. Without significant adoption of renewable energy technologies in the mining industry, most of this new demand will be met with fossil fuels, which would be in opposition to most countries' emission targets. Use of fossil fuels will need to be decreased over the next decade and a half if the mining industry is to realize commitments countries have made to the Paris Agreement and the United Nations' Sustainable Development Goals (which include climate action and sustainable industrialization) as well as individual mining companies emission targets.

Table 1. Cradle-to-Gate Energy Use and GHG Impacts of Select Metals

\begin{tabular}{|c|c|c|c|c|}
\hline Metal & Feed & Process/route & $\begin{array}{l}\text { GER } \\
(\mathrm{KWh} / \mathrm{t})\end{array}$ & $\begin{array}{l}\text { GHG (Mt } \\
\mathrm{CO} 2 \mathrm{e} / \mathrm{Mt})\end{array}$ \\
\hline \multirow[t]{2}{*}{ Gold } & $\begin{array}{l}\text { Refractory ore }(3.5 \mathrm{~g} \mathrm{Au} / \mathrm{t} \\
\text { ore) }\end{array}$ & Refractory ore route & $85,019,200$ & 26,840 \\
\hline & $\begin{array}{l}\text { Nonrefractory ore }(3.5 \mathrm{~g} \\
\text { Au/t ore) }\end{array}$ & Nonrefractory ore route & $55,829,200$ & 17,560 \\
\hline Titanium & Ilmenite (36.0\% Ti) & Becher and Kroll processes & 101,080 & 35.7 \\
\hline Aluminum & Bauxite ore $(17.4 \% \mathrm{Al})$ & $\begin{array}{l}\text { Bayer refining, HalleHeroult } \\
\text { smelting }\end{array}$ & 59,080 & 22.4 \\
\hline \multirow[t]{2}{*}{ Nickel } & Laterite ore $(1.0 \% \mathrm{Ni})$ & $\begin{array}{l}\text { Pressure acid leaching and } \\
\text { SX/EW }\end{array}$ & 54,320 & 16.1 \\
\hline & Sulfide ore $(2.3 \% \mathrm{Ni})$ & $\begin{array}{l}\text { Flash furnace smelting and } \\
\text { Sherritt-Gordon refining }\end{array}$ & 31,920 & 11.4 \\
\hline $\begin{array}{l}\text { Stainless } \\
\text { steel }\end{array}$ & Multiple ores & $\begin{array}{l}\text { Electric furnace and } \\
\text { ArgoneOxygen } \\
\text { decarburisation }\end{array}$ & 21,000 & 6.8 \\
\hline Copper & Sulfide ore $(2.0 \% \mathrm{Cu})$ & Heap leaching and SX/EW & 17,920 & 6.2 \\
\hline \multirow[t]{2}{*}{ Zinc } & $\begin{array}{l}\text { Sulfide ore }(5.5 \% \mathrm{~Pb}, 8.6 \% \\
\mathrm{Zn})\end{array}$ & Electrolytic process & 13,440 & 4.6 \\
\hline & $\begin{array}{l}\text { Sulfide ore }(5.5 \% \mathrm{~Pb}, 8.6 \% \\
\mathrm{Zn})\end{array}$ & Imperial smelting process & 10,080 & 3.3 \\
\hline Copper & Sulfide ore $(3.0 \% \mathrm{Cu})$ & $\begin{array}{l}\text { Smelting/converting and } \\
\text { electro-refining }\end{array}$ & 9,240 & 3.3 \\
\hline Lead & $\begin{array}{l}\text { Sulfide ore }(5.5 \% \mathrm{~Pb}, 8.6 \% \\
\mathrm{Zn})\end{array}$ & Imperial smelting process & 8,960 & 3.2 \\
\hline Lead & $\begin{array}{l}\text { Sulfide ore }(5.5 \% \mathrm{~Pb}, 8.6 \% \\
\mathrm{Zn})\end{array}$ & Lead blast furnace & 5,600 & 2.1 \\
\hline Steel & Iron ore $(64 \% \mathrm{Fe})$ & $\begin{array}{l}\text { Integrated route (BF and } \\
\text { BOF) }\end{array}$ & 6,440 & 2.3 \\
\hline
\end{tabular}

Data sources: Norgate, Jahanshashi, and Rankin 2007; Norgate and Haque 2012

Multiple ores under stainless steel represent pig iron (94\% Fe), chromite ore $(27.0 \% \mathrm{Cr}, 17.4 \% \mathrm{Fe})$, and laterite ore $(2.4 \% \mathrm{Ni}, 13.4 \% \mathrm{Fe})$. GER stand for gross energy requirement, which is the cumulative amount of primary energy consumed from extracting to refining metal. 
Table 1 shows the cradle-to-gate energy use and GHG impacts of select metals worldwide. 3 Based on these data, gold is one of the most energy- and emissions-intensive metals mined today after platinum. This is in large part due to increasing ore depletion, which drives gold miners to extract gold ore from deeper underground. About 3,340 Metric tons (Mt) of gold was produced in 2017, according to World Mining Data (n.d.). Assuming the energy intensity and GHG emissions per ton of gold extracted is still the same as 2007 estimates (see Table 1), then roughly 186 to 283 terawatt hours (TWh) of energy was used to produce gold in 2017, and about 58 to 90 million $(\mathrm{Mt})$ of carbon dioxide $\left(\mathrm{CO}_{2}\right)$ emissions were produced as a result of that mining globally.

While steel requires less energy and produces less $\mathrm{CO}_{2}$ than gold per ton of metal production (Table 1), the high volume of global iron and steel production, as well as the process emissions and high heat requirements in steelmaking, render iron and steel production the highest consumer of energy and producer of GHG emissions within the mining industry. For example, in 2018 crude steel production was about 1,808 million tons (World Steel Association 2019a). Assuming that the energy and emission intensity of steel in 2018 is similar to the intensity in 2007 (Table 1), that would mean the steel industry used about 11,644 TWh of energy and produced about 3,616 million Mt of $\mathrm{CO}_{2}$ emission (see the appendix for production data of other metals).

3 "Cradle to gate" covers raw material extraction to refining (Norgate et al. 2007) 


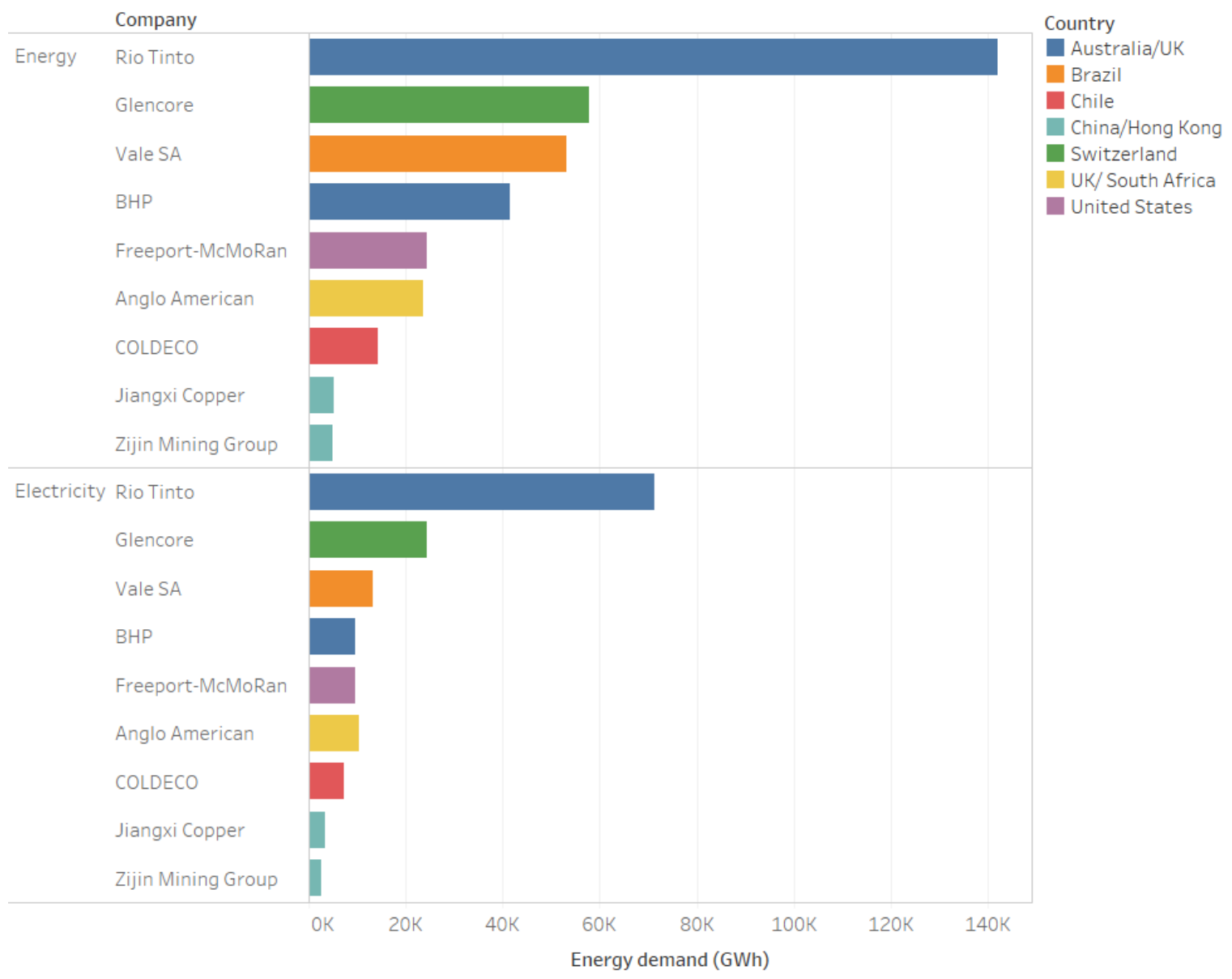

Figure 3. Top energy-consuming miners in the world

Data source: BNEF 2019

The Energy row represent non-electricity consumption.

Figure 3 shows energy consumption of the top mining companies worldwide. The data illustrate that while electrical consumption by mines is significant across the board, these companies use a significant amount of energy that is not electricity. This presents an opportunity to electrify more loads on the mine site and supply these loads with renewables.

\subsection{Renewable Energy Use in Mining}

Figure 4 shows renewable project trends from 2000 to 2019. (Before 2000, the use of renewables in mining operations was nearly nonexistent.) Recent years have seen an uptick in renewable energy adoption by mining companies, with a notable spike in commissioned projects in 2019 . The renewable installation by mining companies has increased from $42 \mathrm{MW}$ of annual installation in 2008 to 3,397 MW of annual installations in 2019 (BNEF 2019). 


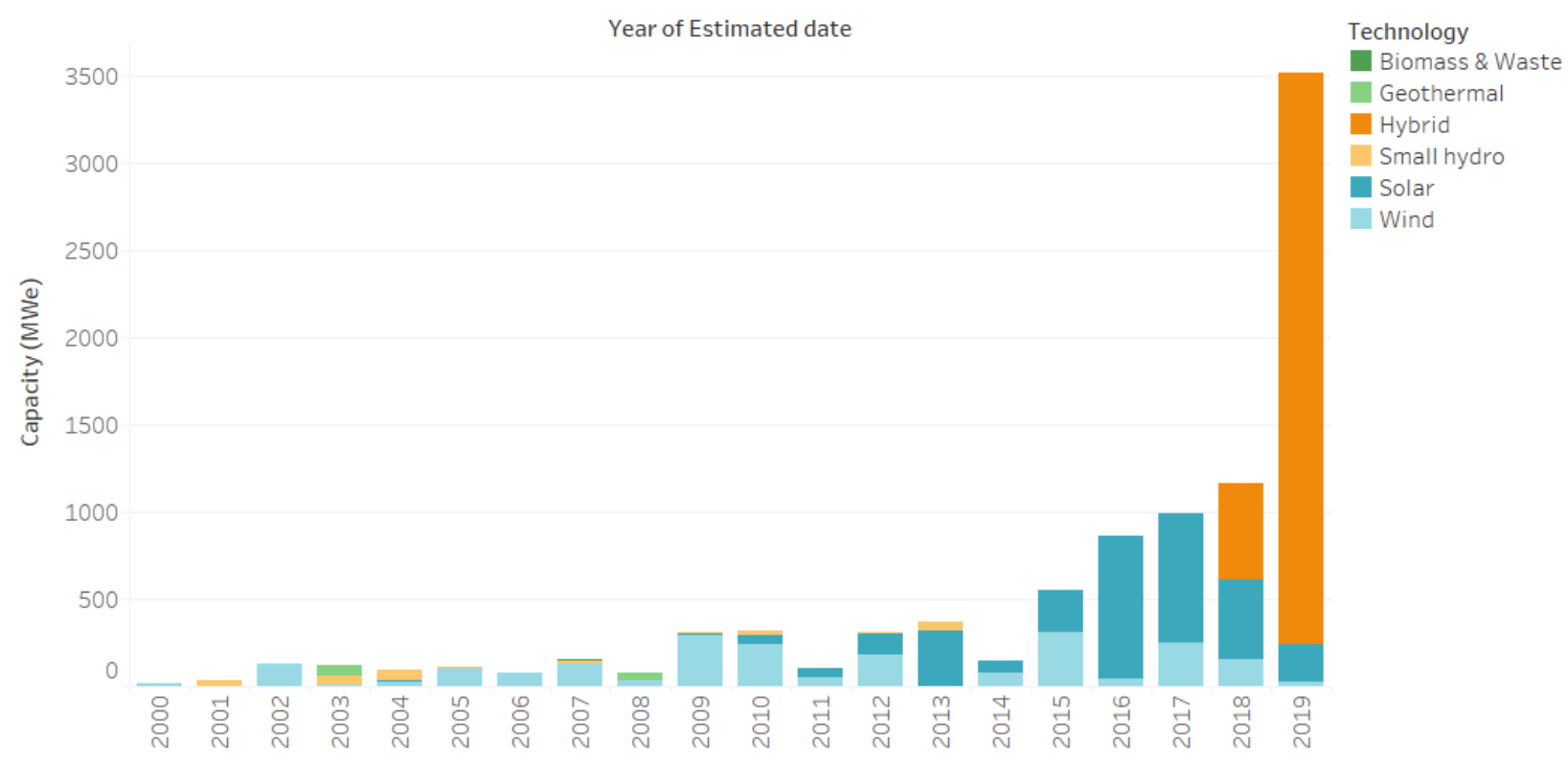

Figure 4. Renewable projects associated with mining companies worldwide

Data source: BNEF 2019

Most of the systems in 2018 and 2019 are hybrids - i.e., a combination of wind, solar, energy storage, and other technologies - generally backed by fossil fuels to smooth the variability of the renewable energy generation (see Figure 4). For single technology applications, solar has the highest installed capacity, followed by wind energy. Around $85 \%$ of these projects are owned by mining companies. The remaining $15 \%$ are either contracted through PPAs or other means in which the mining company is an off taker (see Figure 5). Approximately $73 \%$ of these projects are off-site while $27 \%$ are on-site.

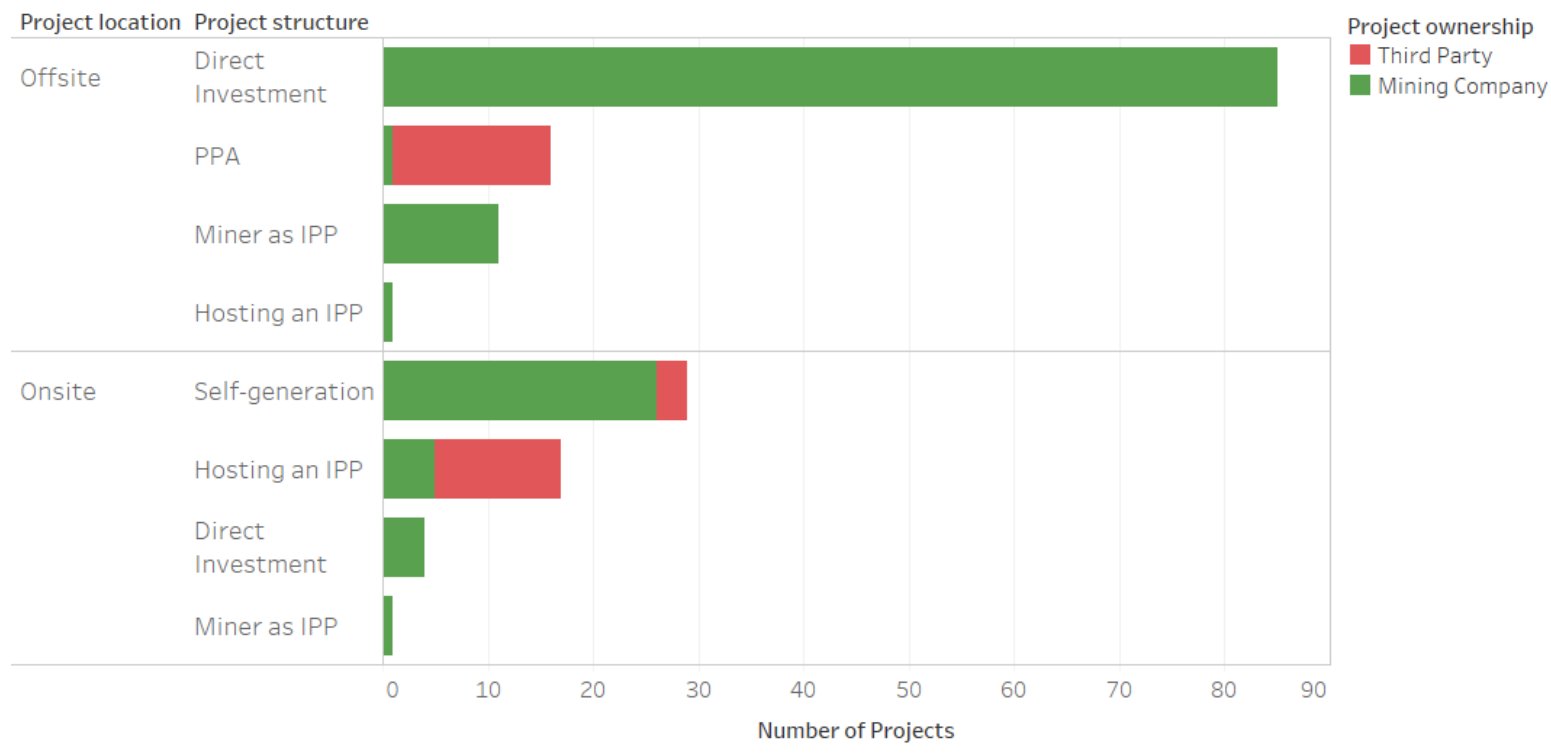

Figure 5. Renewable project business model

Data source: BNEF 2019 
Figure 6 shows the mining companies associated with the renewable energy projects highlighted in Figure 4 and their status. BHP and NLC India Ltd lead the sector in commissioned renewable projects. Despite this increase in renewable project installations, the aggregate amount of energy generated by these projects is still a fraction of total energy consumed by the mining industry (see, for example, Figure 3).

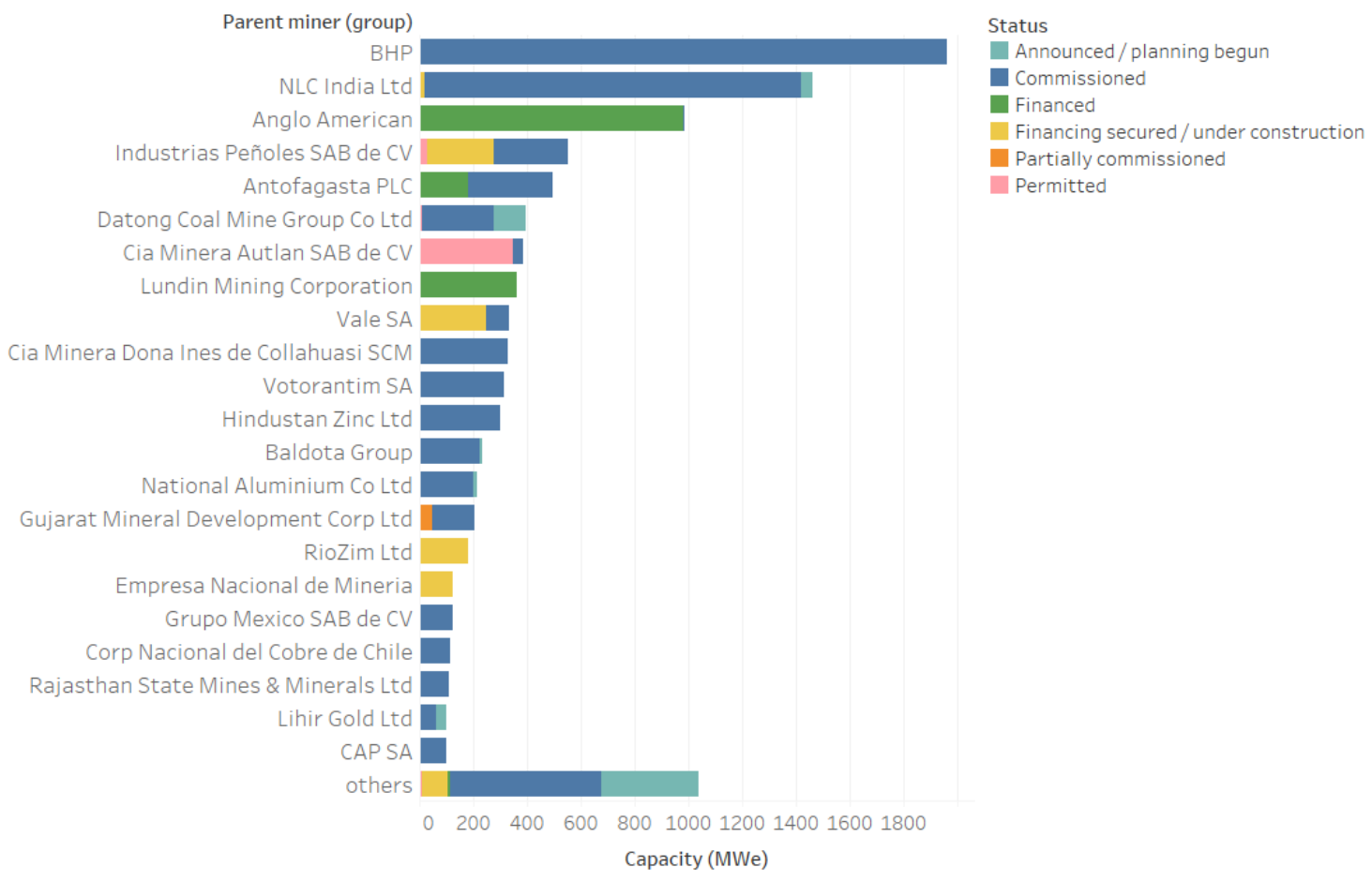

Figure 6. Renewable projects associated with mining companies worldwide

Data source: BNEF 2019

Mining companies owns both offsite and onsite renewable projects. 


\section{Trends and Challenges Shaping the Mining Industry}

This section discusses the principal issues shaping the mining industry today and how these are driving interest in renewable energy use in mining operations.

\subsection{Declining Ore Grades}

Depletion of higher grade and easily accessible ores has driven mining companies to seek resources that are more remote and deeper in the ground. Falling ore grades also means more materials need to be extracted, loaded, hauled, transported, and processed than would otherwise be necessary to produce the same amount of metal or minerals. This intensifies the energy requirements for mine operations. For example, a decrease in copper ore grade between $0.2 \%$ and $0.4 \%$, will require seven times more energy than present-day operations (Lezak, Cannon, and Koch 2019).

Studies suggest that declining ore grades, combined with increasing demand for metals, will exacerbate the GHG emissions impact from primary metal production (Norgate and Haque 2010). This presents a challenge for the mining industry, which is contending with the dual challenges of seeking decarbonization measures while at the same time facing the prospect of growing energy demand. Additionally, the increasing remoteness of mines presents energy supply chain issues, which can have GHG and cost impacts in the form of available fuel types, transportation needs, site access and infrastructure measures, and other logistical considerations.

\subsection{Volatile Prices}

The mining industry is very susceptible to supply and demand shocks that affect energy and metal prices, because they affect the cost of production and revenue. Ultimately, increasing costs and decreasing revenues can translate to thinner profit margins. Energy is one of the largest expenses in mining. On average, this expense ranges from $15 \%$ to $40 \%$ of the total operational cost (Maennling Toledano 2018). Fossil fuels comprise 57\% of global energy consumption by the mining and quarrying sectors, $33 \%$ from oil products, $13 \%$ from coal, and $11 \%$ from natural gas. Electricity (from various sources) accounts for $40 \%$ of global energy consumption by the mining and quarrying sectors and heat some 3\% - mostly generated from combustible fuels (Alova 2018). Fossil fuels supplied to many mining operations must be imported, which makes them susceptible to exchange rate and tariff risks, supply chain logistics, and geopolitical risk. For example, between 2011 and 2014, oil was mostly trading above $\$ 100$ per barrel but has since dropped to below $\$ 60$ per barrel (see Figure 7). Energy price fluctuations, in combination with declining metal prices, present major concerns for mining industry profitability (see the appendix). ${ }^{4}$

\footnotetext{
${ }^{4}$ As of this writing, the coronavirus pandemic has sent global demand, oil and gas prices tumbling (Mason, Luk, and Hinton 2020; Sell 2020). While such a drop in operating costs might otherwise be beneficial for the mining industry, global demand for metals has also plummeted, leading to revenue shortfalls. This situation is rapidly unfolding, and it remains to be seen what the long-term ramifications of these shocks will be for commodity prices and the mining and metals industry at large.
} 


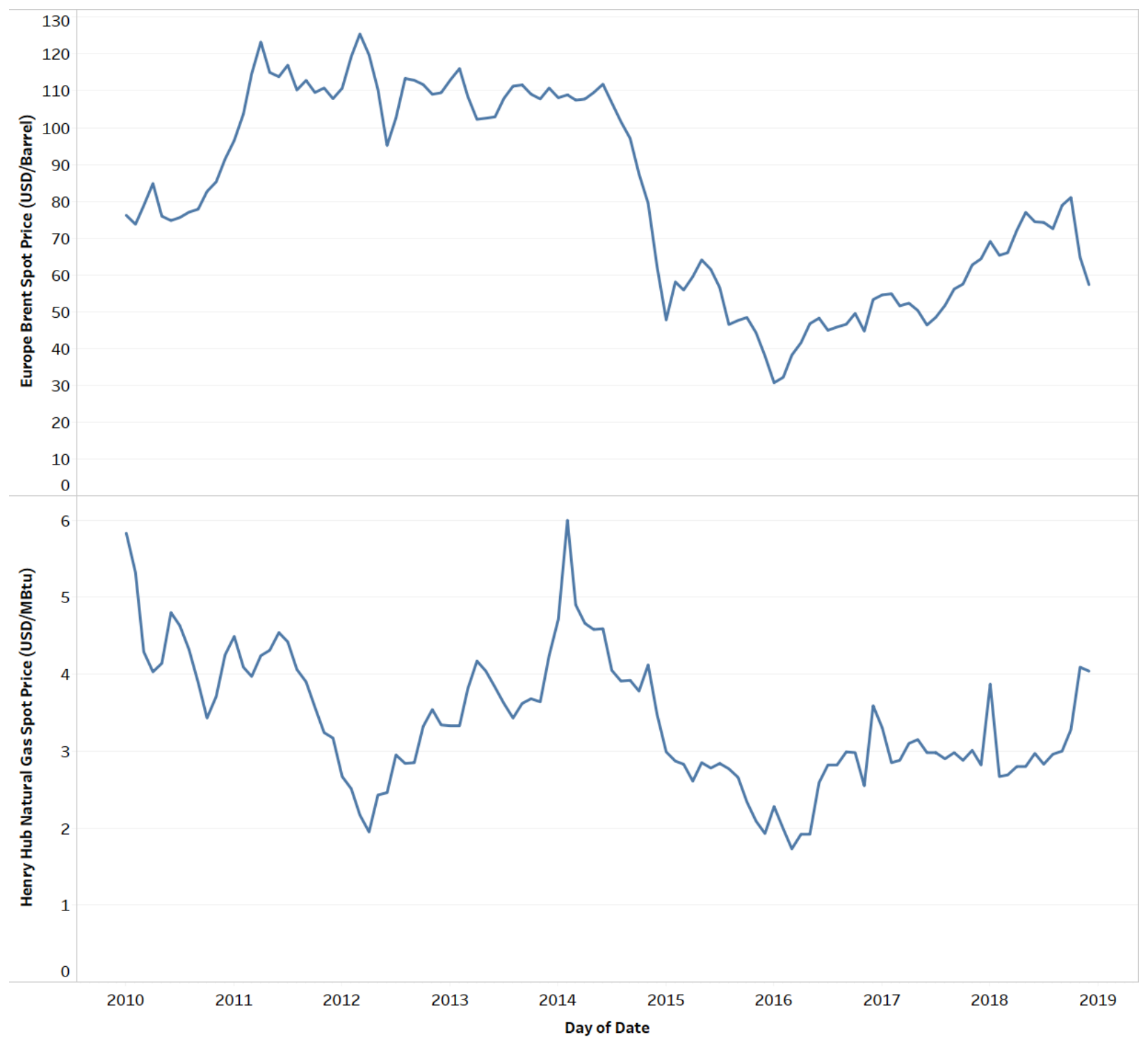

Figure 7. Example of fossil fuels price fluctuations

Data source: EIA 2019a and EIA 2019b

\subsection{Increasing Environmental Concerns}

The mining industry poses significant environmental impacts, both at the local and global levels, generated by mining operations in two ways: (1) energy used by mining activities, such as GHG emissions and (2) mining activities such as blasting and processing (resulting in mining waste containing toxic chemicals from processing). These mining activities can lead to soil erosion, land use impacts, air pollution, and contamination of water sources and soil (Sahu, Prakash, and Jayanthu 2015). As the industry searches for more difficult-to-extract mineral resources in ecologically sensitive areas, environmental concerns are expected to increase the level of scrutiny. This is one of the reasons that the International Council on Mining and Metals (ICMM) requires its members to address environmental concerns (Davy 2018). 


\subsection{Increasing Political and Social Concerns}

At the same time, the mining industry is experiencing increasing pressure from its shareholders and external stakeholders to reduce dependence on fossil fuels at all points along the supply chain. These stakeholders include international organizations, host governments, local communities, and end-use product producers (metal buyers) such as major electronics and renewable energy technology manufacturers.

Recognizing the important role that the mining industry can play in achieving emissions targets, host countries are beginning to require more stringent pollution controls and statutory reporting requirements (e.g., the inclusion of the effects of energy consumption in environmental impact assessments required for obtaining an operating permit). For example, host governments of leading mineral producers such as Canada, Australia, Chile, and others are creating enabling policies and regulations such as carbon taxes, green certifications, and flexible dispatch to accommodate renewable sources integration (Norton Rose Fulbright 2017; Natural Resource Canada 2019; ARENA 2019).

The communities in which mines operate are beginning to mobilize as well, advocating not only for their local air and water quality, but also for a lasting, sustainable energy infrastructure from which they could benefit after the mine closes operations. Accordingly, as energy demand for mine operations increases in the coming years, so too will the need to source generation that addresses stakeholder concerns. 


\section{Renewable Integration Opportunities}

Renewable energy technologies such as wind and solar have recently become the least-expensive source of power on a levelized cost of energy (LCOE) basis in many parts of the world, and capital costs for these also continue to fall (Lazard 2019). Accordingly, integrating renewable generation into mining operations may offer an opportunity for companies to not only decarbonize operations, but also to improve operating margins and reduce risks associated with fossil fuel volatility. Mining companies and national governments can also realize secondary effects with renewable energy, such as stimulating local economic development, improving social license to operate, and creating shared value. We divide renewable integration opportunities in the mining industry into two main categories, those for mining operations and those for mining communities.

\subsection{Opportunities for Mining Operations}

Several mining operations activities rely on electric power, but most electricity generation is fossil fuel-fired, thus, may be powered by renewable energy. While on-grid mining operations may have no choice in their source of electricity (in this case, greening grid systems could be a viable option), off-grid mining operations and back-up electricity for on-grid could benefit from renewable integration into their operations. Also, mining operations in both grid-connected and off-grid sites use fossil fuels directly as source of energy or feedstock that can benefit from renewable sources (see, for example, Table 2).

Table 2. Example of Mining Processes and Associated Fuel Sources

\begin{tabular}{|c|c|c|}
\hline Mining process & Activities and Equipment & Fuel Source \\
\hline \multirow{5}{*}{$\begin{array}{l}\text { Exploration, } \\
\text { Extraction and } \\
\text { Auxiliary Operations }\end{array}$} & $\begin{array}{l}\text { Ventilation: HVAC (heating, ventilating, and } \\
\text { air conditioning) }\end{array}$ & Electricity and Natural Gas \\
\hline & $\begin{array}{l}\text { Drilling: Loader trucks, diamond drills, rotary drills, } \\
\text { percussion drills, drill boom jumbos }\end{array}$ & $\begin{array}{l}\text { Electricity, Diesel, and } \\
\text { Compressed Air }\end{array}$ \\
\hline & Dewatering: Pumps & Electricity \\
\hline & $\begin{array}{l}\text { Digging: Hydraulic shovels, cable shovels, continuous } \\
\text { miners, longwall mining machines, drag lines, front-end } \\
\text { loaders }\end{array}$ & Electricity and Diesel \\
\hline & Power supply: Generators & Fossil Fuel \\
\hline \multirow[t]{2}{*}{ Material Handling } & $\begin{array}{l}\text { Discrete transportation systems: Haul trucks, service } \\
\text { trucks, bulldozers, pickup trucks, bulk trucks, load-haul } \\
\text { dumps, shuttle cars, hoists }\end{array}$ & Diesel and Electricity \\
\hline & $\begin{array}{l}\text { Continuous transportation systems: Conveyor belts, } \\
\text { pumps, pipelines }\end{array}$ & Electricity \\
\hline \multirow{6}{*}{$\begin{array}{l}\text { Beneficiation and } \\
\text { Processing }\end{array}$} & Comminution & Electricity \\
\hline & Crushing: Crushers & \\
\hline & Grinding: Mills & \\
\hline & $\begin{array}{l}\text { Separations: Physical: Floating, centrifuge; and Chemical: } \\
\text { Electrowinning }\end{array}$ & Electricity and Fossil Fuels \\
\hline & Drying, Firing, Smelting: Oven/Furnace & Fossil Fuels \\
\hline & Refining e.g., Electrolytic refining, fire refining & Electricity and Fossil Fuels \\
\hline
\end{tabular}


For example, in the United States, most of the primary metal and nonmetallic mineral production uses fossil fuels for various operations beyond extraction (see Figures 8 and 9). ${ }^{5}$ Metal production generally consumes more energy than nonmetallic minerals. The bulk of this energy consumption (about $70 \%$ ) is from the iron and steel industry, followed by the alumina and aluminum industry at $14 \%$ (EIA 2014). For nonmetallic mineral production, most energy is consumed by the cement industry at $30 \%$, followed by glass industries at $14 \%$ and the lime industry at $12 \%$.

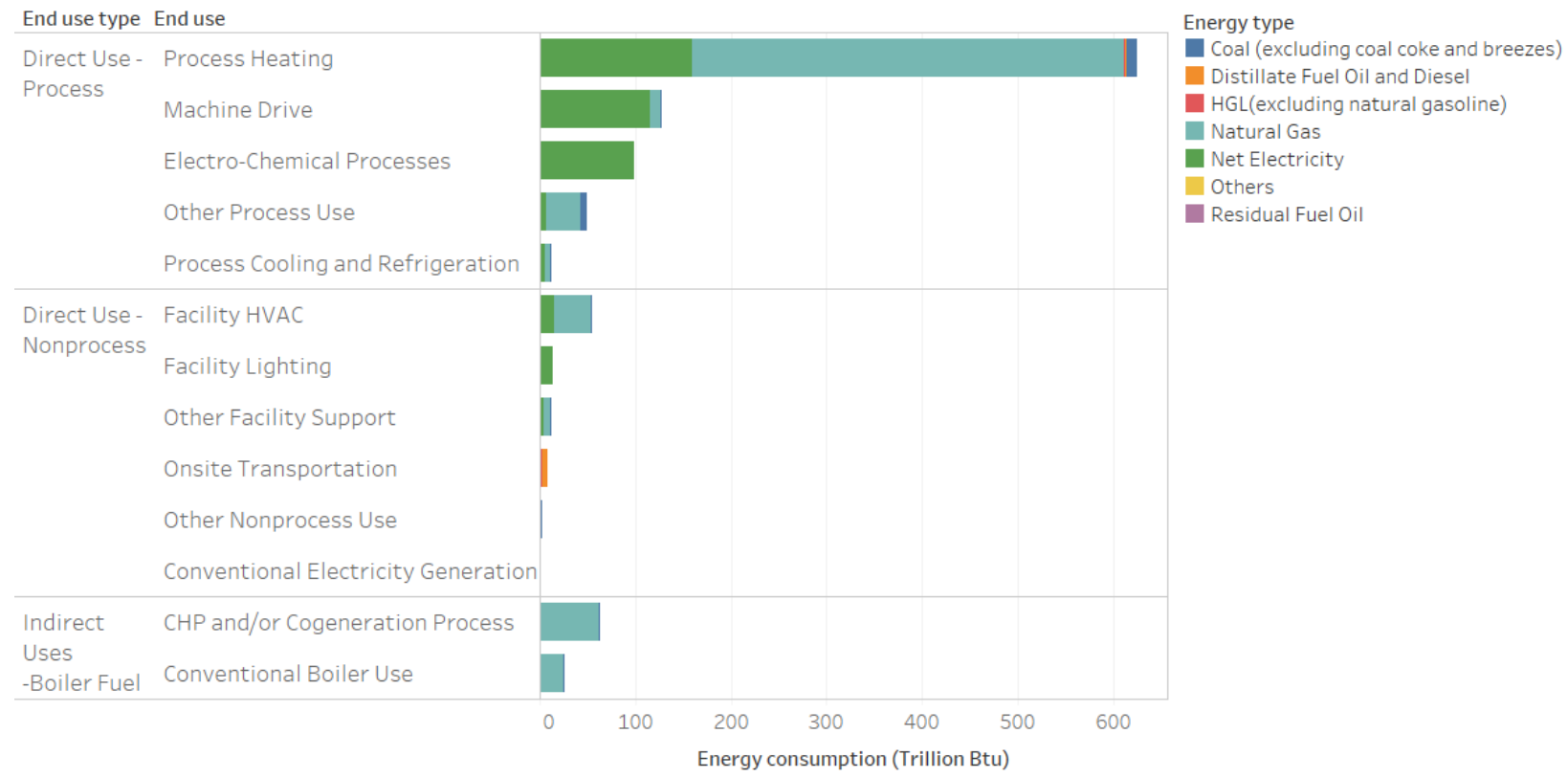

Figure 8. Primary metal production energy use in the United States

Source: EIA 2014

Figure 8 and Figure 9 also show that most of this energy is used for process heat, with a significant amount sourced from fossil fuels (mostly natural gas and coal in the United States). This implies that a significant reduction of fossil fuel used in the mining operation can be achieved by targeting process heat, though, as discussed in Section 5.2, this presents some challenges.

After natural gas, electricity is the second major source of energy in U.S. primary metal production, and is primarily used for process heat, machine drive and electrochemical processes. Likewise, in nonmetallic mineral production, most of the electricity is used for machine drive and process heat. In contrast to process heat, this electricity load can be readily supplied with renewable energy, particularly hybrid systems or virtual crediting contracts that can smooth the variability of the generation profile.

\footnotetext{
${ }^{5}$ These figures only cover energy as fuel use; most data for non-fuel uses for metal and nonmetallic mineral production are withheld by the EIA to avoid disclosure of individual establishments. These figures do not include energy consumed for ore extraction processes (activities under NAICs code 21), and only cover metal and nonmetallic manufacturing (NAICs code 327 and 331) and processing.
} 


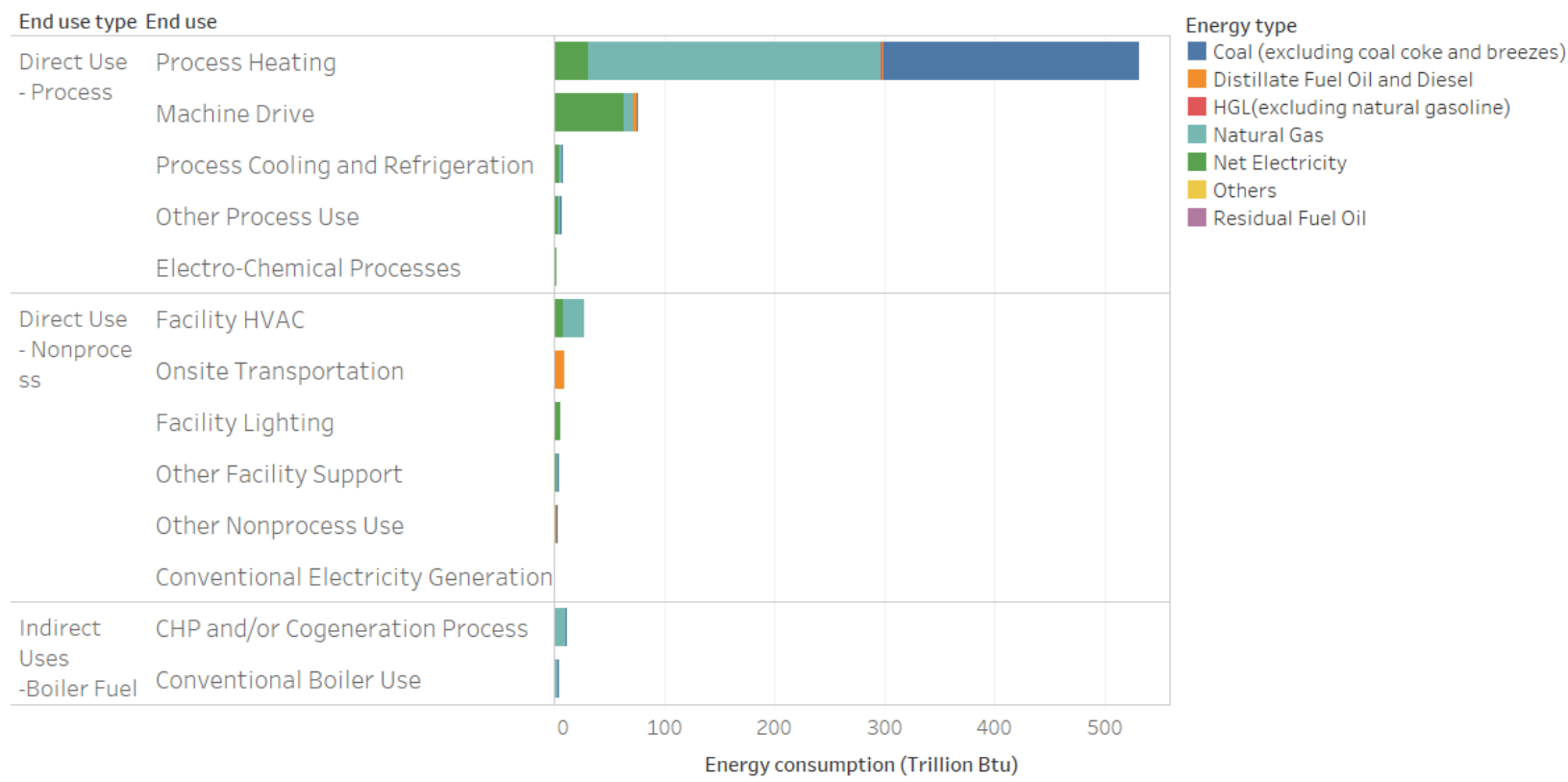

Figure 9. Nonmetallic mineral production energy use in the United States

Source: EIA 2014

\subsubsection{Renewables for Electricity Demand}

Renewables can play a role in displacing HFO, diesel, and coal used in generation for electricitydependent mining operations (see Table 2 and Figure 7). For example, comminution activity (the process of reducing ore and/or rock to desired sizes by mechanical means) is one of the most energy-intensive activities in mining, and any attempt to reduce the carbon footprint of mining should address these (DOE 2007). Katta, Davis, and Kumar (2020) estimated that comminution uses about an average of $15 \%$ of total energy demand in iron mining and an average of $21 \%$ of total energy demand in gold production. Fortunately, comminution is almost exclusively electrified, making it easier to address with renewable sources. Katta, Davis, and Kumar (2020) also indicated that underground mining ventilation systems use significant electricity —in gold production, about $20 \%$ of total energy demand by the gold production is used in ventilation. In the United States, a significant quantity of electricity is used for processing metals, especially to generate process heat, for machine drive and electrochemical processes (see, Figure 7). But a bulk of this electricity generated in the United States comes from fossil fuel-at about 63\% (see, for example, Figure 10). For off-grid mining operations, electrifying this electricity load is within their control, but for on-grid operations, this opportunity may not apply. Rather, greening the grid will be a viable option; this is out of scope for this report, but this topic has been covered extensively by other studies such as Palchak et al. 2017. 


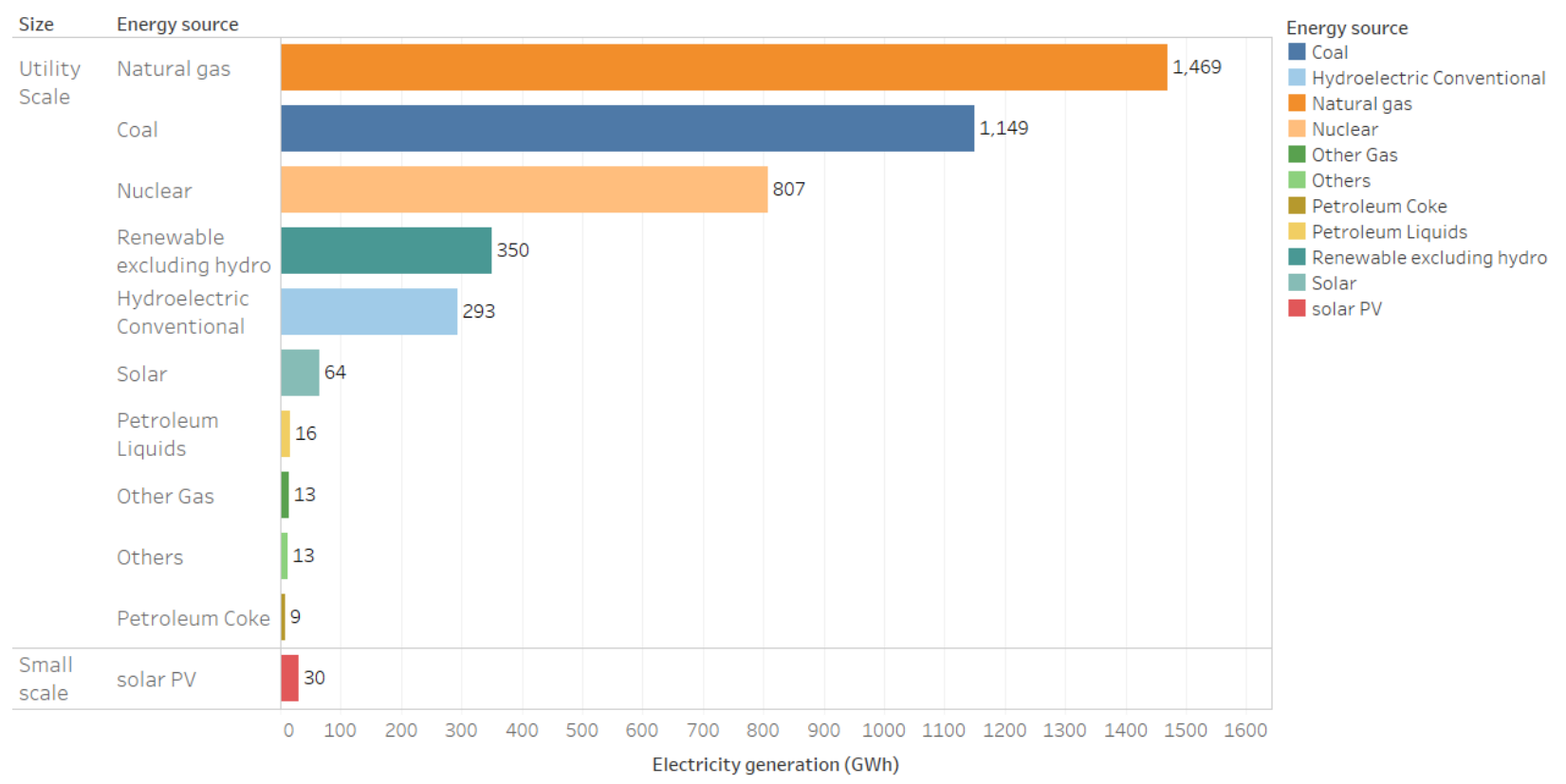

Figure 10. Total U.S. net electricity generation energy sources for all sectors, 2018

Source: EIA 2014

Most electricity is generated from natural gas and coal. Most small-scale solar PV are usually installed on building rooftop and are usually located near the location of consumption

Electricity generation for off-grid operations or onsite backup for on-grid operations can be powered with renewables sources. (For on-grid operations, in certain markets where applicable, excess renewables electricity can be sold back to the grid.) Renewables are becoming an increasingly appealing option for remote, off-grid operations that have available resources (e.g., sun, wind, geothermal). Rio Tinto is planning to build a $34 \mathrm{MW}$ solar PV with $12 \mathrm{MWh}$ lithiumion battery system to meet its electricity demand in their Koodaideri mine in Pilbara, Australia (Deign 2020). This system will meet about $65 \%$ of the Koodaideri mine's electricity demand during peak hours. Success stories of mines using geothermal power in remote sites of Papua New Guinea, wind power in the Arctic of northern Canada, and solar power in the Outback of Australia and West Africa illustrate the effectiveness of renewables in serving remote facilities (Booth and Bixley 2005; Judd 2014; Slavin 2016).

\subsubsection{Renewables to Replace Fossil-Fueled Heat and Transportation}

Certain mining industry activities depend on direct combustion of fossil fuels. In this case, fossil fuel is used to generate heat for mining processes such as firing in iron mining or as fuel to power equipment used for ventilation, hauling and onsite transportation (see Figure 11). Some of these activities may be transitioned to electric loads with the electricity provided by renewable technologies while others may use renewable energy directly. 


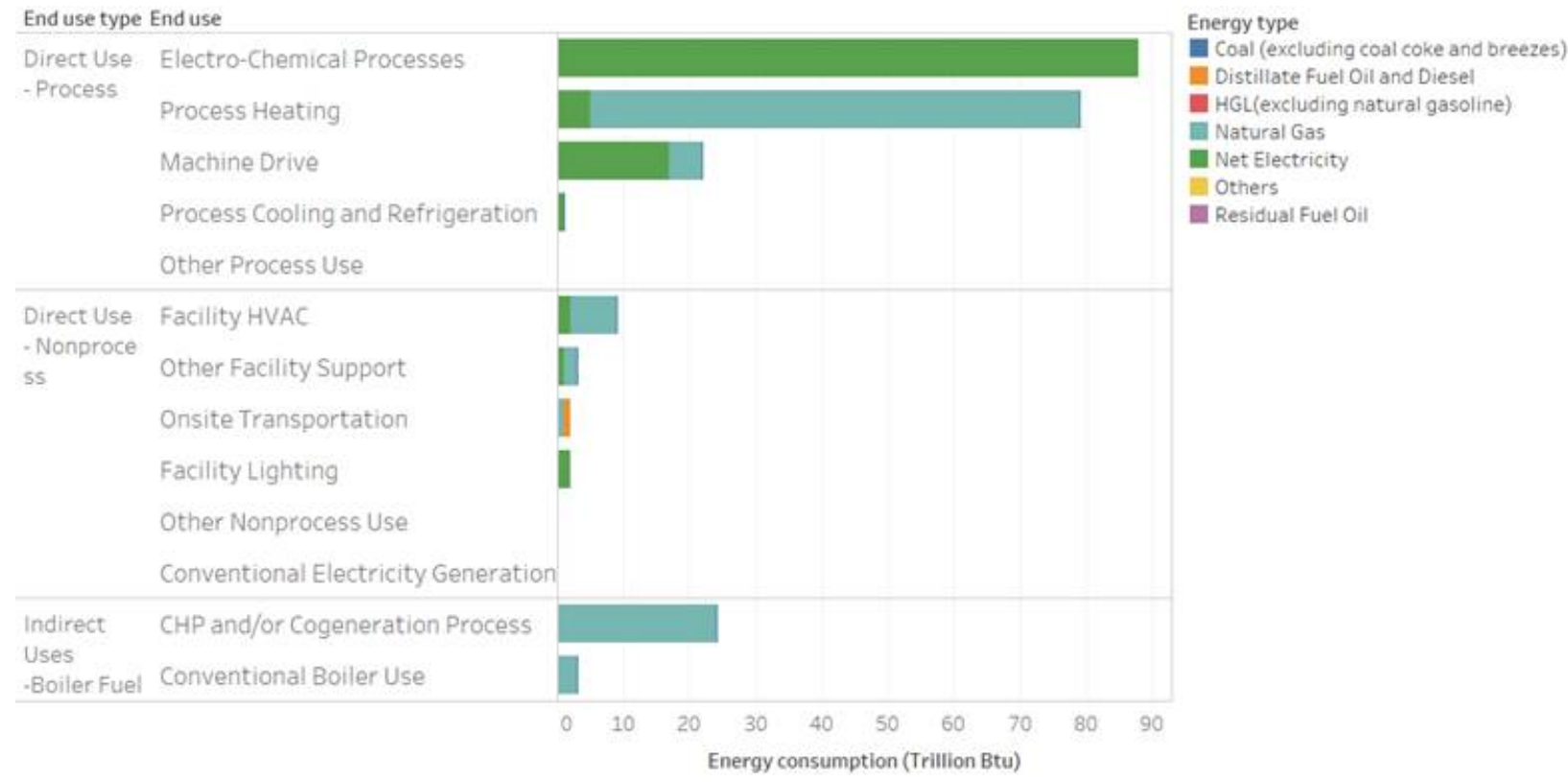

Figure 11. Alumina and aluminum production energy use in the United States, 2014

Source: EIA 2014

Table 2 categorizes these loads under auxiliary operations, material handling, beneficiation, and processing. While material handling may not be energy intensive in mineral manufacturing, as shown in Figure 8, Figure 9, and Figure 11, in ore production, energy consumption by material handling is significant and will need to be addressed if the mining industry is to reduce its carbon footprint. Transport and haulage, for example, use about $10 \%$ of total energy demand in gold production and iron ore extraction (Katta, Davis, and Kumar 2020). Integrating renewables into material handling is more challenging because diesel fuel is still a significant source of energy for many of these activities, particularly for truck-haulage. However, the industry has started to use battery-powered and biodiesel trucks and load-haul-dumps and is also exploring hydrogenpowered haulage. Currently, underground mines are leading the way in this regard because of the need to comply with diesel particulate matter emissions standards. This motivation does not exist for surface mines that also have larger pieces of equipment. Additionally, electrifying mobility for underground mines can result in economic offsets in the avoided cost of ventilation equipment. Surface mines can benefit from technologies such as electric trolley-assist combined with other solutions (biodiesel and energy recovery during braking on the downhill haul) to reduce fossil fuel use.

\subsubsection{Renewables for Feedstock Demand}

Some mining activities require fossil fuels as feedstock in their production processes. Coal and natural gas comprise the majority of feedstocks in the mining industry, and-while it is challenging for renewables to entirely displace these-some studies suggest that renewable sources can supply $20 \%-30 \%$ of fossil fuel feedstock demand for industrial minerals, and ferrous-alloy and nonferrous metal producers (IRENA 2015). For example, steel production using smelting reduction largely relies on coal as feedstocks to produce coke needed in blast furnaces $(\mathrm{BF})$ and blast oxygen furnaces $(\mathrm{BOF})$. Around $70 \%$ of global steel produced comes from $\mathrm{BF}$ and $\mathrm{BOF}$ route. On average, $1,000 \mathrm{~kg}$ of crude steel produced by this route uses $780 \mathrm{~kg}$ of metallurgical coal (World Steel Association 2019b). Additionally, both coal and natural gas 
are used as reducing agents in the direct reduced iron (DRI) production process. In a gas-based DRI plant, natural gas is combined with water and heat to develop hydrogen and carbon monoxide needed to convert iron ore to DRI, while in a coal based DRI plant, carbon from coal is used to as a reducing agent. ${ }^{6}$ Biomass and clean hydrogen produced by renewables present an opportunity to substitute fossil fuel feedstocks in some activities, such as hydrogen reduction in iron and steel making.

\subsubsection{Production of Clean Hydrogen}

Hydrogen has many uses in the mining industry such as generating high-temperature heat, power, feedstock, fuel for transportation and other mining equipment, and energy storage. Currently, it is largely produced from natural gas, coal, and oil (IEA 2019). For mining operations with the capability to install variable renewable energy technologies such as wind and solar, excess electricity could be converted to hydrogen and stored for other mining activities. For example, the European Marine Energy Centre and the Orkney Islands demonstrated converting excess electricity from wind turbines into hydrogen stored in a fuel cell to provide dispatchable green power (Jackson and Molloy 2018).

\subsection{Opportunities for Mining Communities and the Circular Economy}

Rapid growth of renewable technologies also presents synergistic opportunities between the mining industry, local and national governments, and the renewable industry. Most renewable energy technologies use materials that are considered critical—i.e., they are of strategic importance to certain industries and have a certain degree of supply chain risk. These include minerals such as cobalt, lithium, nickel, and rare earth metals. For most of these materials, substitution with another metal or mineral is either technically infeasible or reduces the effectiveness of the technology.

Supply risk for these materials is partly caused by political instability and environmental concerns. Most mining activities are located in unstable countries (see Figure 12). The communities where many mine sites operate are generally rural and agricultural. Sharing renewable energy with communities around mines will stimulate economic activities by encouraging agri-business, which will create jobs, leaving lasting impact to communities. This can promote social and political stability in mining communities and countries.

Where renewables can reduce mining costs (by downsizing energy expenditures), this reduction can increase a host country's competitiveness, which, in turn, can encourage more in-country processing operations. This has been strategically important for many mining countries as, at present, most raw minerals are exported to places where lower energy costs and more reliable energy supply render processing more economic. ${ }^{7}$ This deprives many countries of the additional value that could be gained from mineral sector. One of the inhibitors of increasing in-country mineral processing in mining countries is the lack of affordable and reliable energy. Renewable

\footnotetext{
${ }^{6}$ MIDREX brochure: MIDREX Process: The World's Most Reliable and Productive Direct Reduction Technology. April 2018. https:/www.midrex.com/wp-content/uploads/MIdrex_Process_Brochure 4-12-18.pdf.

${ }^{7}$ UN Comtrade Database. Accessed 2020: https://comtrade.un.org/data/.
} 
energy could improve mining communities and countries where materials are produced, as well as help secure the supply chain of raw materials used in renewable technologies.

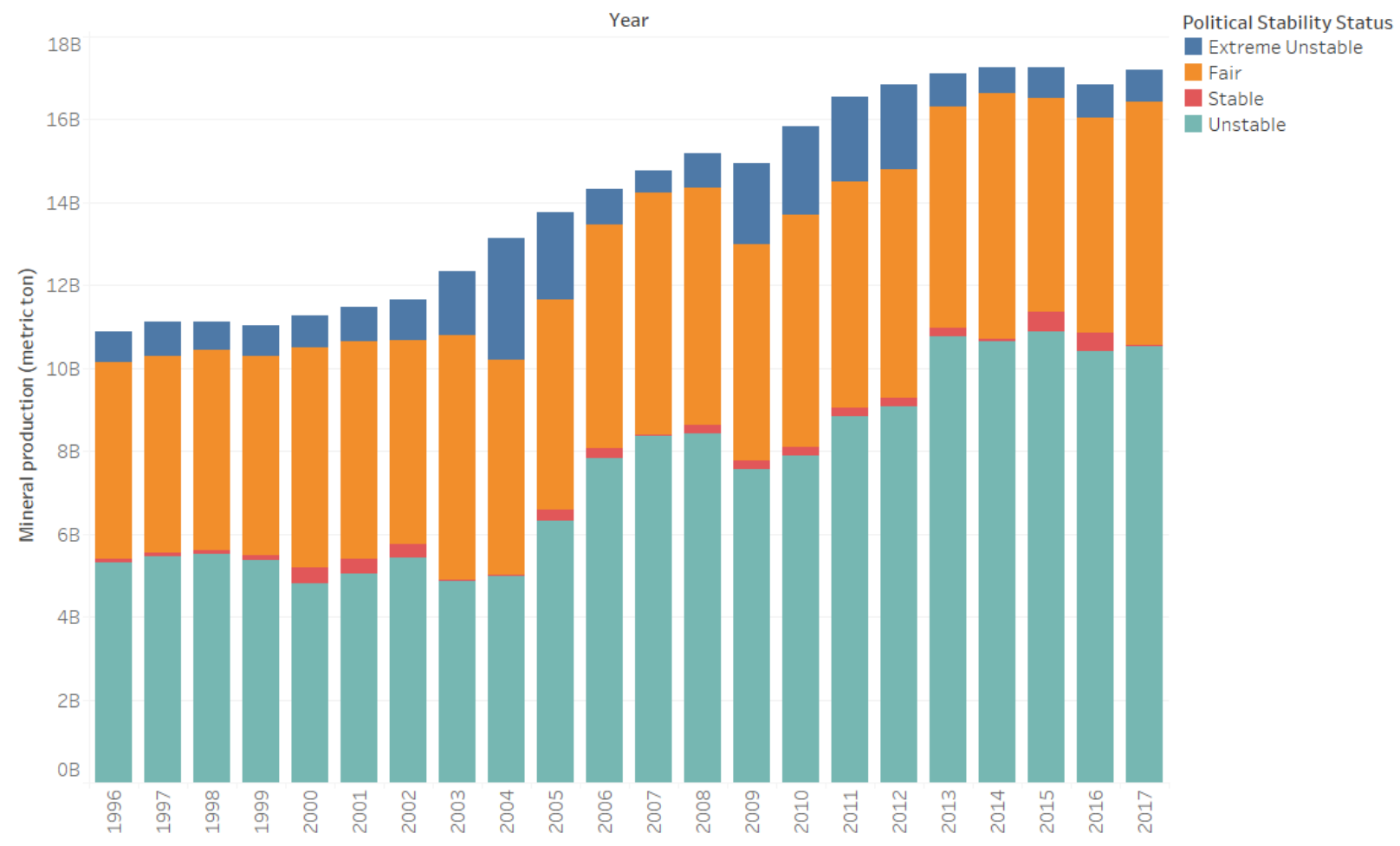

Figure 12. Worldwide mining activities and political stability status

Data source: World Mining Data (n.d.) 


\section{Technical Considerations for Renewable Integration in Mining Operations}

Renewable energy use in the mining industry is growing, but there remain technical challenges that limit the quantity of renewable energy that can serve operational loads. The bulk of the mining industry's energy demand requires careful evaluation when considering renewable integration. This section presents some of these considerations when planning renewable integration in mine operations.

\subsection{Feedstock Demand}

Mining operations that require fossil fuels as a feedstock are usually hard to fully decarbonize with current renewable technologies. Technology advancement is still needed to allow for higher penetration levels. While biomass (charcoal) can be used as a feedstock alternative in some operations, global sustainable production of charcoal, transport cost of charcoal to plant sites, and other technical aspect of charcoal use in steelmaking are still major concerns (Norgate et al. 2012; de Pee et al. 2018). Hydrogen also presents an alternative feedstock to fossil fuels in some mining operations such as DRI and BF, which is a much better source in terms environmental impact than biomass when produced using water and renewable electricity. But producing hydrogen using renewable sources at the scale required by the mining industry is still expensive. More R\&D investments are needed to help reduce cost of clean hydrogen that could be used in metal processing. For example, commercial use of hydrogen as a substitute for carbon monoxide in steel making is not expected until 2030s (IEA 2019).

\subsection{Process Heat Demand}

Process heat demand is one of the major energy consuming processes within the mining industry. Process heat requirements for the mining industry spans the spectrum from low- to hightemperature. Industrial low-temperature heat is defined as below $150^{\circ} \mathrm{C}$; medium-temperature as temperature between $150^{\circ} \mathrm{C}$ and $400^{\circ} \mathrm{C}$; and high-temperature above $400^{\circ} \mathrm{C}$ (IRENA 2015; IEA 2019). This variability of process heat demand dictates technology selection at the mine site. For example, in steel production, a temperature between $800^{\circ} \mathrm{C}$ and $1,200^{\circ} \mathrm{C}$ is used in the reduction of iron oxide to metallic iron. In the copper smelting process, a heat temperature of about $250^{\circ} \mathrm{C}$ to $350^{\circ} \mathrm{C}$ is used in roasting copper ore to copper oxide. During the aluminum extrusion process, aluminum billets are heated to soft solids at a temperature of between $400^{\circ} \mathrm{C}$ and $500^{\circ} \mathrm{C}$. Low- to medium-temperature heat is generally produced through steam, while direct heat (mostly through the combustion of fossil fuels) is used to produce high-temperature heat (IRENA 2015).

Currently, high-temperature industrial requirements are generally fulfilled by fossil fuels $-65 \%$ using coal, 20\% natural gas, and 10\% oil (IRENA 2015; IEA 2019).

As shown in Table 3, most renewable energy technologies currently deliver low or medium temperature process heat and are thus only applicable for some process requirements.

Concentrated Solar Power (CSP) technology is showing promising results but will require larger land availability and sufficient solar resources. Currently, commercial application of CSP can achieve process heat temperatures up to around $550^{\circ} \mathrm{C}$ (Ericson, Engel-Cox, and Arent 2019). However, more experimental CSP facilities such as the Heliogen Lancaster California facility has demonstrated temperatures in excess of $1,000^{\circ} \mathrm{C}$ (Spector 2019). Also, researchers at the Barbara Hardy Institute have developed a new technique that could help lower this fossil fuel 
dependency in high-temperature process heat production. Through their pilot system, they demonstrated that renewable energy from hybrid systems (solar and wind energy, coupled with thermal energy storage) could deliver industrial temperatures between $150^{\circ} \mathrm{C}$ and $700^{\circ} \mathrm{C}$ (Jacob et al. 2019). This could serve the demand for many metal processing activities that require medium- to high-temperatures, such as nonferrous metal production like copper smelting and aluminum extrusion.

Currently, the only commercially available renewable solution for high-temperature process heat in excess of $550^{\circ} \mathrm{C}$ can be delivered by biomass (charcoal or CHP). Charcoal can generate heat temperature of up to about $1,260^{\circ} \mathrm{C}$ (Cheng et al. 2016). But as mentioned in Section 5.1, biomass fuel sources such as charcoal or wood are not without limitations. Clean hydrogen is a potential technology for high-temperature heat requirements, but currently clean production of hydrogen is largely uneconomical (IEA 2019). Hydrogen is also an attractive emissions-free source of energy for several mining activities beyond generating heat (e.g., Jackson and Molloy 2018 and Zakharia 2020).

Table 3. Commercially Available and Economical Renewable Energy Technologies

\begin{tabular}{lll}
\hline Category & Technology Type & Temperature Levels \\
\hline Renewable source & Biomass, boiler & Low \\
& Biomass, high temperature & Medium \\
& Biomass, CHP & High \\
& Biogas, anaerobic digestion & Low \\
& Solar PVa & High \\
& Wind & High \\
& Heat pump & Low \\
& Geothermal direct use & Low \\
& Deep geothermal & Medium \\
& Solar thermal & N/A \\
Energy storage & Hydrogen & N/A \\
& Pump storage & N/A \\
& Battery storage & N/A \\
\hline
\end{tabular}

Sources: NREL estimates supplemented by IRENA 2015, University of Australia 2019, and U.S. Environmental Protection Agency (EPA).

Low temperature $\left(150^{\circ} \mathrm{C}\right)$, medium temperature $\left(150^{\circ} \mathrm{C}-400^{\circ} \mathrm{C}\right)$, and high temperature $\left(>400^{\circ} \mathrm{C}\right)$.

a High temperature heat production using solar and wind beyond $550^{\circ} \mathrm{C}$ is not yet commercially offered, and is still in the demonstration phase at research facilities

\subsection{Constant Energy Demand}

Mining operations require significant, high quality and generally constant energy supply, often 24 hours a day and seven days a week. This is a barrier integrating large shares of variable renewable energy. These variable renewable energy technologies such as wind and solardepending on their capacity in relation to mine site electricity demand - may overproduce during 
peak generation hours, which can lead to complexities with utilizing the excess energy. Some of this extra energy may be stored if the mine has a system (e.g., batteries, hydrogen electrolysis). If the mine is grid-connected and has a net metering or grid export agreement with the system operator, they may be able to sell the excess energy. However, most of the time this extra energy is curtailed. ${ }^{8}$

To manage variability mines will often turn to hybrid system generally supported by onsite diesel generators, which reduce fossil fuel use but do not eliminate it entirely. ${ }^{9}$ For example, the mining town of Coober Pedy in Australia operates a hybrid wind (4 MW), solar (1 MW), and battery storage $(1 \mathrm{MW} / 500 \mathrm{kWh})$ powerpack that has displaced about $70 \%$ of diesel (Maennling and Toledano 2018). For many mines, it only makes economic sense to integrate renewables to cover part of their load, for example, between $30 \%$ and $40 \%$ of total electricity demand -- using current renewable and control technologies (Guilbaud 2016).

Although the use of renewable energy technology can clearly reduce the need for carbon-based energy use at mines - especially those with exceptional renewable resources such as wind, hydropower or solar or with high energy costs - over the near term it is not likely to provide deep decarbonization of mining operations. Continued efforts to further lower the cost of renewable power and energy storage, combined with the expansion of mine operators' ability to effectively address the integration of variable energy generation, will be needed.

\subsection{Mining Industry Design and Investment Structure}

Most mining operations make investment decisions that account for life of the mine, which may range from 2 to more than 50 years. This period is a critical input into the mine's return on investment calculation (Statista 2020). Most of the major decisions in mine planning and design are usually done during pre-feasibility and feasibility phases. Once these designs are executed and the mine site is constructed, the operating company is locked into the selected technology and capacity (i.e., size) for a while. Even making changes to the mine development plan after the investment decision has been made can be challenging as plan changes require many levels of approval and may cause ripple effects in other parts of the design plan.

Most mining production activities are based on an all-or-nothing approach, meaning the mine will produce at capacity as long as they are meeting their operation expenditure (OPEX), because they have already incurred the capital investment. Once they have ability to change their capital investment (CAPEX) for mining expansion, there is room for flexibility. This feature of mining operations has implications in integrating renewable energy. For example, the blast furnace-basic oxygen furnace (BF-BOF) route in steel manufacturing accounts for around $70 \%$ of global steel production. Many of the processing plants utilizing this technology were built in the past 10 to 20 years and have long lifespan, and it would be costly to integrate renewable energy into their

\footnotetext{
${ }^{8}$ Current battery technologies do not support more hours of storage. More batteries could be purchased to store more energy but usually project economics do not support such option. Moreover, net metering or some other export compensation mechanism can be difficult for mining projects to obtain for various reasons, including lack of regulatory framework allowing for grid exports; size limitations in jurisdictions where net metering is available; low compensation rates in certain jurisdictions; and other challenges.

${ }^{9}$ Examples include solar PV-battery-diesel hybrid system, wind-battery-diesel hybrid system, and solar-windbattery-diesel system (Maennling and Toledano 2018)
} 
existing operations before the end of their design life (de Pee et al. 2018). In this case, other solutions such as $\mathrm{CO}_{2}$ abatement or energy efficiency could be more appropriate instead of electrifying their fossil fuel loads (for example, converting to electric furnaces) with renewable electricity (de Pee et al. 2018). ${ }^{10}$ However, renewable energy may demonstrate competitive economics when installed as part of a mine expansion or when planning new operations (i.e., if renewable energy solutions are evaluated as part of the design and feasibility study processes). ${ }^{11}$ For example, Oz Minerals and Cassini Resources from Australia through their pre-feasibility study indicated that their proposed new copper nickel mine located in West Musgrave, Australia will be powered by up to $80 \%$ renewables. The companies propose to use a hybrid system of solar-wind-battery-diesel which produce 220,000 tons per annum less $\mathrm{CO}_{2}$ emission than a fully diesel-powered operation (Spence 2020).

\footnotetext{
${ }^{10}$ However, at the moment, $\mathrm{CO}_{2}$ abatement technologies are still costly, but if R\&D enable cost reduction, BF-BOF could benefit from this technology.

${ }^{11}$ At a workshop held for mining stakeholders at the National Renewable Energy Laboratory in 2019, participants identified a lack of training and education resources for mine engineers to evaluate renewable energy as part of overall mine design. This is a gap that mining schools and engineering programs could address with updates to their curricula. It could also be an opportunity for professional training and certification organizations to supply this knowledge to the marketplace.
} 


\section{Case Studies on Renewable Integration Opportunities}

Renewable integration opportunities will generally require some customization depending on the particular mining operation, its location relative to available renewable resource and onsite energy requirements of the mine. This section highlights loads that could benefit from integrating renewables for two types of mining operations: iron and gold. These two were selected based on their environmental impact, and the benefits that renewable energy can confer on their GHG content. It should be noted that the disaggregated energy data used in this section-even from reliable sources such as Natural Resource Canada and U.S. benchmarking studies - have several discrepancies (Levesque, Millar, and Paraszczak 2014). Nevertheless, these data provide valuable insight of average energy consumption by these activities. Actual energy consumption by a specific activity and mining company could be higher or lower than those reported herein.

\subsection{Iron and Steel Production}

Iron and steel production are divided into three main parts: ore mining, iron making and steel making. All these parts are energy intensive (with a significant amount of this energy sourced from fossil fuels), and consequently generate high GHG emissions. Table 4 displays disaggregated electricity demand per ton in iron mining while Figure 13 displays disaggregated fossil fuel use. Several iron mining activities are powered by electricity. Katta, Davis, and Kumar (2020) indicate that, in 2016, about 39\% of the total energy used by Canada's iron ore mining sector came from electricity.

Table 4. Disaggregated Electricity Loads by Iron Ore Mining

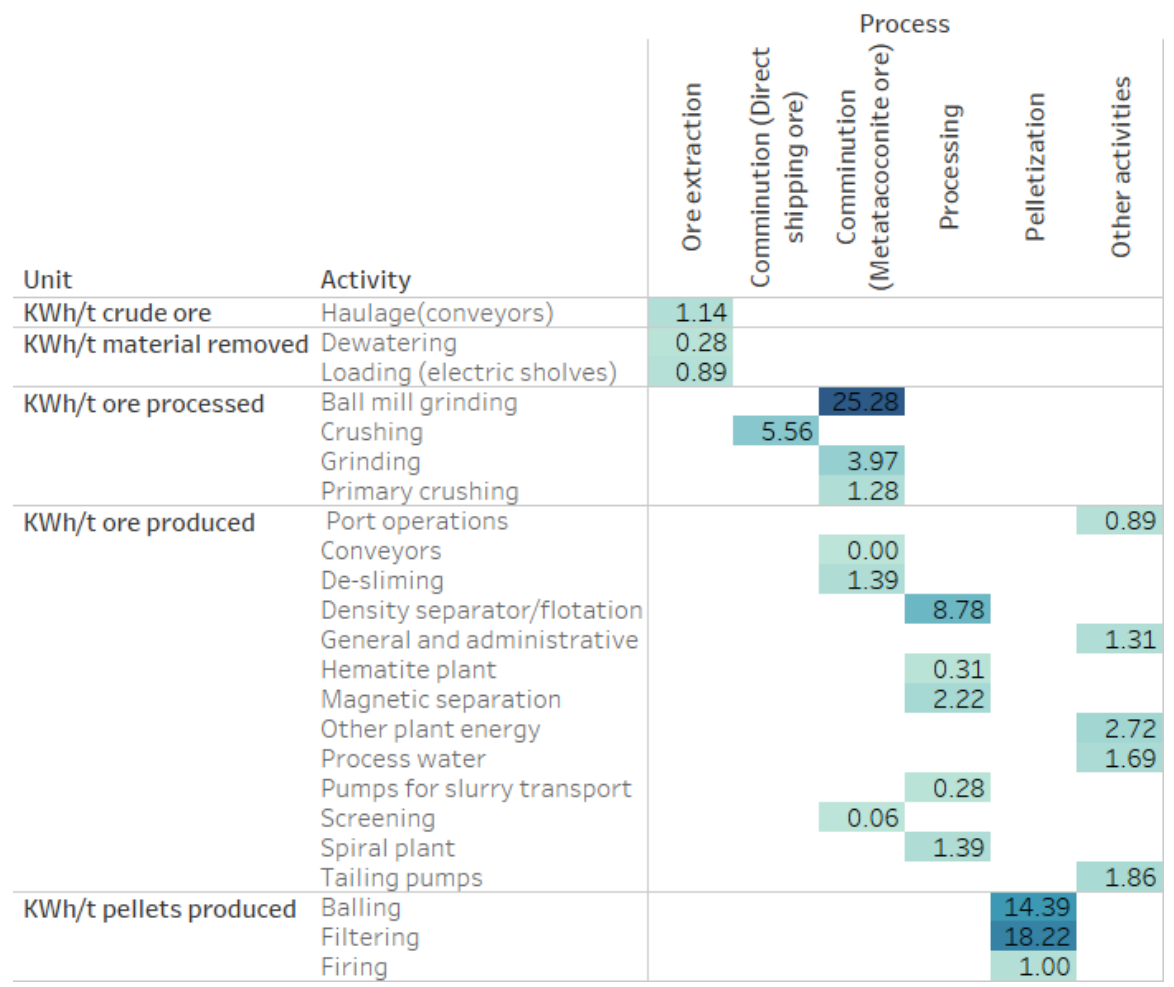

Data sources: Katta, Davis, and Kumar 2020 as compiled from several sources such as Natural Resources Canada, U.S. Department of Energy, and other studies 
The comminution and pelletization processes consume a significant amount of this electricity per ton (see Table 4). Iron ore production with renewable resource such as solar, wind, and geothermal could produce some of this electricity needed by the activities highlighted in Table 4 using renewables. Because no change in the mining processing system will be required, renewable electricity could be applied to existing, as well as to new mining sites. Analysis using tools such as REopt will need to be done to determine optimal renewable integration based on the mine load profile and location.

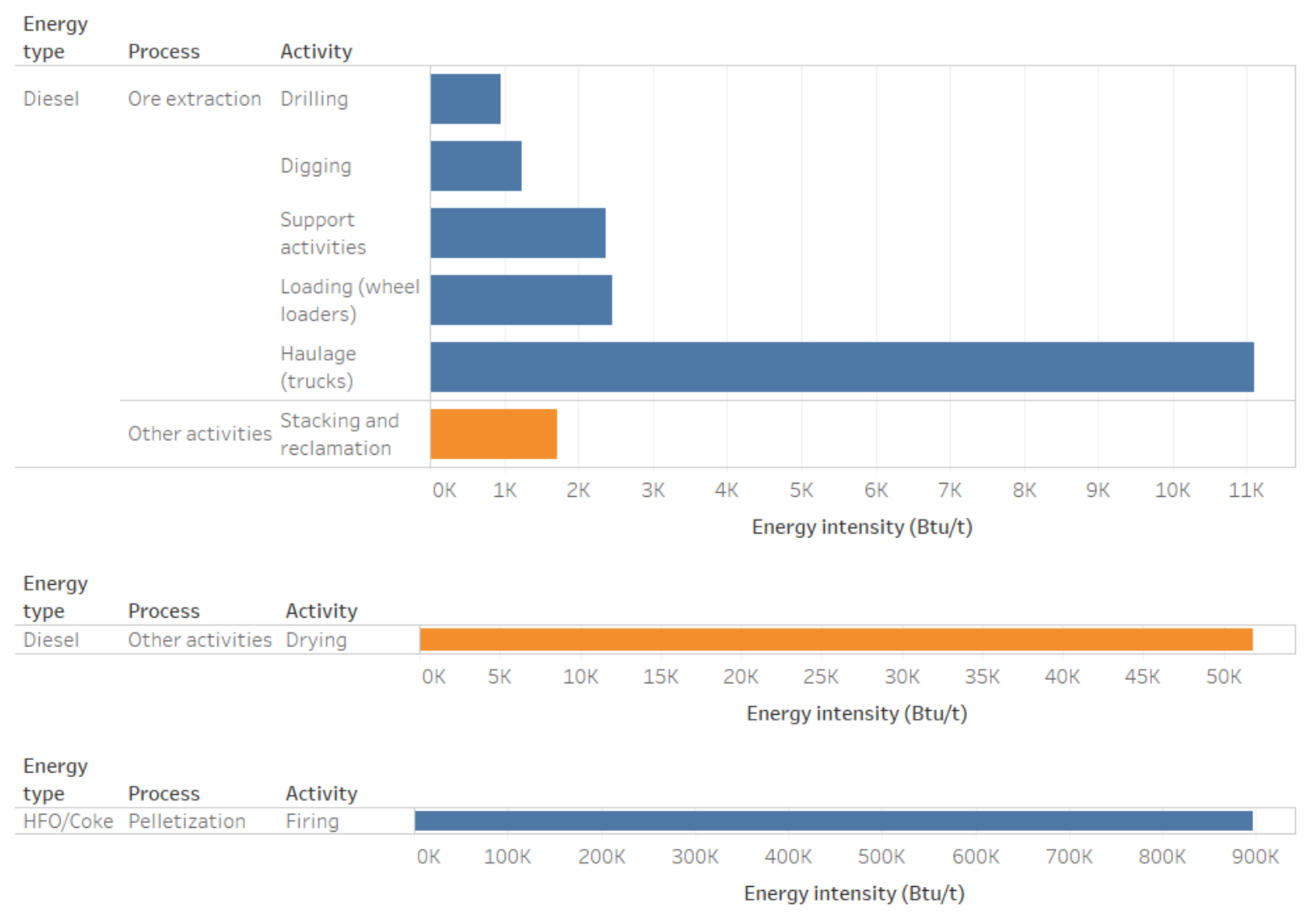

Figure 13. Fossil fuel use in iron mining

Data sources: Katta, Davis, and Kumar 2020 as compiled from several sources such as Natural Resources Canada, U.S. Department of Energy, and other studies. 3412.14 Btu is equivalent to $1 \mathrm{kWh}$.

Iron ore mining also uses a significant amount of direct fossil fuels, as shown in Figure 13. For example, the heavy fuel oil or coke that is used in palletization accounts for about $896,808 \mathrm{BTU} / \mathrm{t}$ $(\approx 263 \mathrm{kWh} / \mathrm{t})$ of pellets produced. In 2016 , firing activities accounted for about $42 \%$ of total energy used by the Canadian's iron ore mining sector. Drying is another activity that uses a significant amount of fossil fuel, typically diesel fuel, at about $51,856 \mathrm{BTU} / \mathrm{t}(\approx 15 \mathrm{kWh} / \mathrm{t})$ of material produced. These activities are medium to high temperature processes up to $300^{\circ} \mathrm{C}$ for drying and with roughly up to $1,350^{\circ} \mathrm{C}$ for pelletizing (de Moraes et al. 2018). For iron mining sites with availability of sunlight and supporting geology, deep geothermal and CSP technology could deliver the drying heat demand. Commercially available CSP cannot completely replace heavy fuel oil and coke use for high temperature process but, as mentioned in Section 5, promising technologies can produce heat above $1,000^{\circ} \mathrm{C}$. While it is not yet economical to produce clean hydrogen at a scale needed by mining operations, hydrogen created with 
renewable energy could be used to meet demands for high temperature heat. ${ }^{12}$ Given that the issues are typically financial, mining sites with very good renewable energy resource availability and high energy costs could explore deploying renewable energy where excess renewable energy produced during peak hours could be used to create hydrogen that can be stored and combusted to generate required heat.

A significant amount of energy in iron and steelmaking is used in process heat. In the United States, these industries comprise about $8 \%$ of total energy consumed by the manufacturing industry, and account for about $70 \%$ of total energy used by primary metal industries (IEA 2014). As shown in Figure 14, most of this is used directly for process energy (about $35 \%$ of total energy used in iron and steelmaking). The United States has made great strides in electrifying steel furnaces by processing scrap. Over $60 \%$ of the steel produced in the United States is produced using an electric arc furnace (U.S, Department of Energy). Even still, the bulk of energy used in iron and steelmaking is supplied from natural gas.

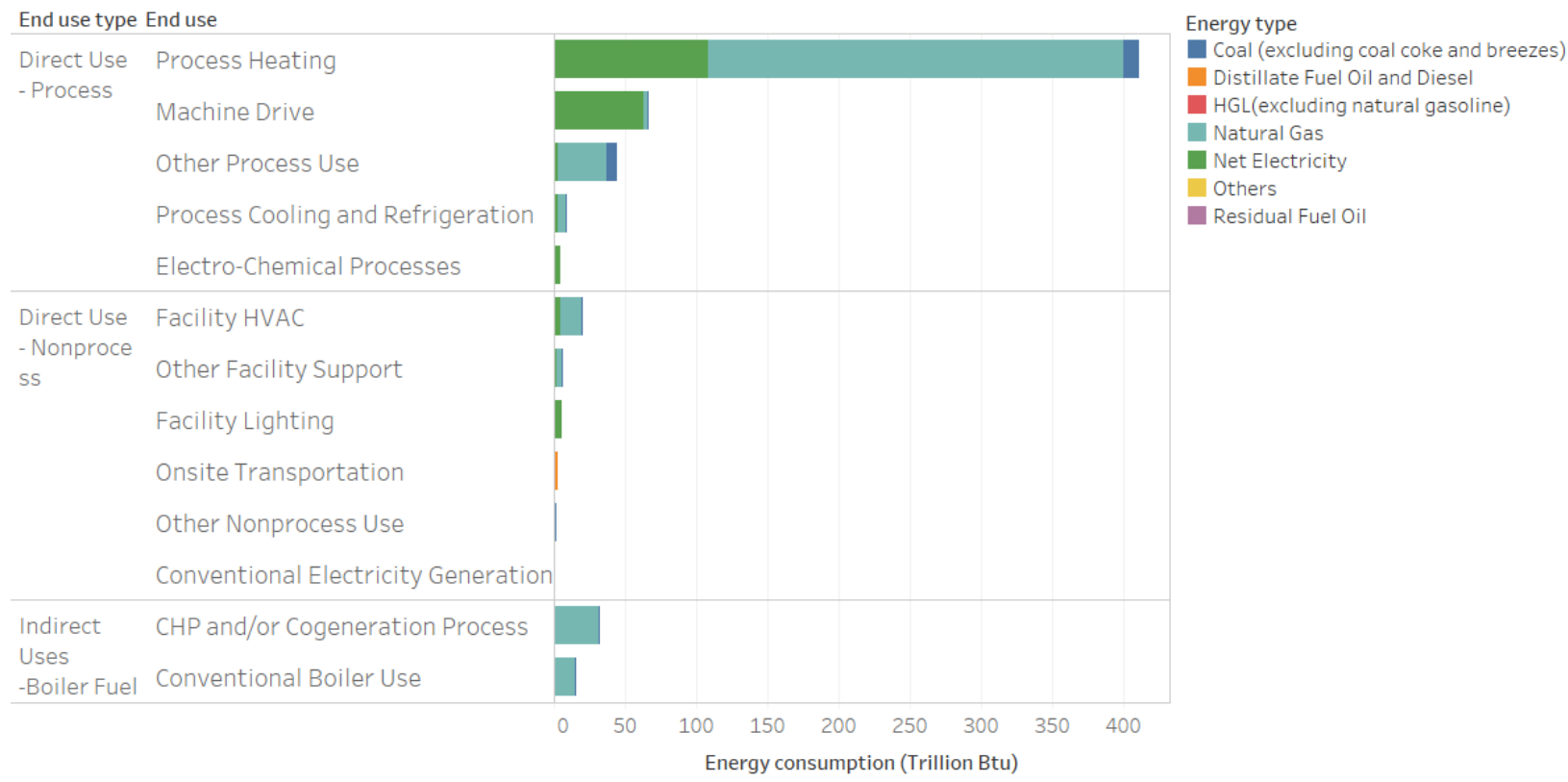

Figure 14. Iron and steel production energy use in the United States

Source: EIA 2014

There may be limitations on electrifying some iron and steel production loads with renewables, especially for existing operations for primary iron and steel production. Further miningoperation-specific analysis would be needed to determine the economics and technical viability of renewable options, both for new mines or as a way to reduce costs and carbon emissions at existing facilities. For new or future projects, a strong focus on demonstrating recent technology innovations in process electrification that have been applied in other sectors could be explored to expand the applicability of these clean energy sources options. Other fossil fuel intensive activities that are more unique to mining, such as digging, drilling, haulage and loading, should

\footnotetext{
${ }^{12}$ Green heating and cooling: https://hydrogeneurope.eu/green-heating-and-cooling
} 
also be analyzed to better understand the applicability of process electrocution, expanding the ability to take advantage of low-cost renewable sources if available.

\subsection{Gold Production}

Gold production is the most energy and GHG emission intensive metal per unit produced, and this characteristic is likely to persist with the depletion of high-grade gold reserves.

Unlike iron and steel production, which use a large amount of fossil fuels for feedstock processing and process heat, gold production uses a much higher contribution of electricity, presenting more opportunities for renewables integration (Table 5). The high use of electricity for gold production provides a viable opportunity for gold producers to consider where possible efficiency measures and then to fulfill a portion of this electricity demand with renewables sources

Table 5. Example of Disaggregated electricity Loads by the Gold Production

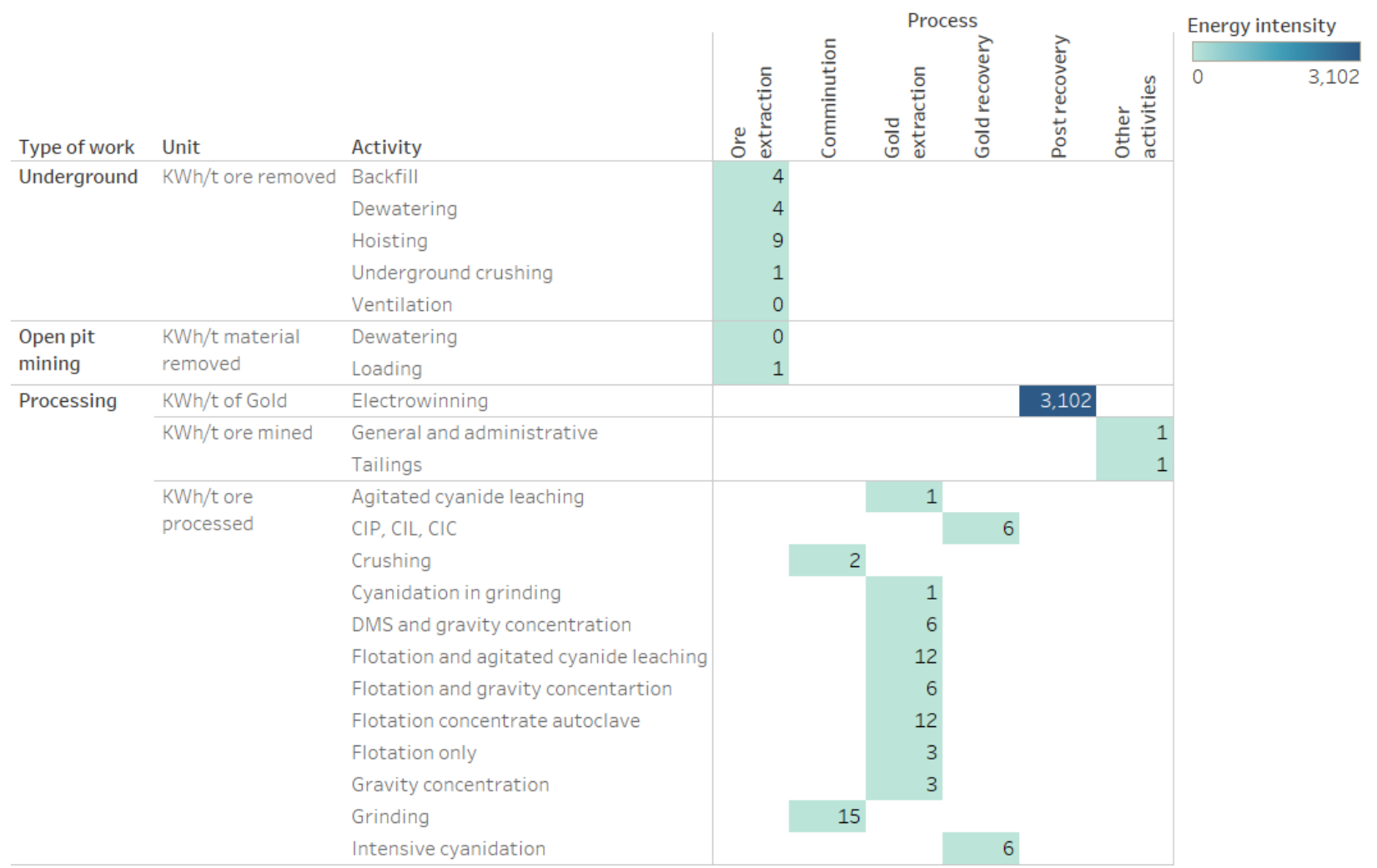

Data sources. Katta, Davis, and Kumar 2020 as compiled from several sources such as Natural Resources Canada, U.S. Department of Energy, and other studies

$1 \mathrm{kWh}$ is equivalent to $3412.14 \mathrm{Btu}$.

The majority of fossil fuel use stems from underground gold ore extraction (see Figure 15). Particularly relevant in underground operations in Canada are activities such as: drilling (roughly $8 \mathrm{kWh} / \mathrm{t}$ ore removed); mucking (roughly $6 \mathrm{kWh} / \mathrm{t}$ of ore removed); and transportation (6 $\mathrm{kWh} / \mathrm{t}$ from an underground mine and $113 \mathrm{kWh} / \mathrm{t}$ from an open pit mine). Many of these activities can be electrified, allowing the use of more renewable based energy sources. Additionally, as the industry extracts more gold from underground reserves, the higher energy intensity of 
underground mining will further increase energy consumption. Thus, expanded consideration of energy efficiency, paired with renewable integration into material handling in underground mines, are bound to significantly reduce the energy intensity and carbon footprint for gold extraction. In an effort to improve mine air quality, underground mines are already actively engaged in electrifying their activities due to pressure to reduce diesel particulate matter. Mill heating could be powered with renewables in areas with strong resources (e.g., high wind speeds or solar irradiation).

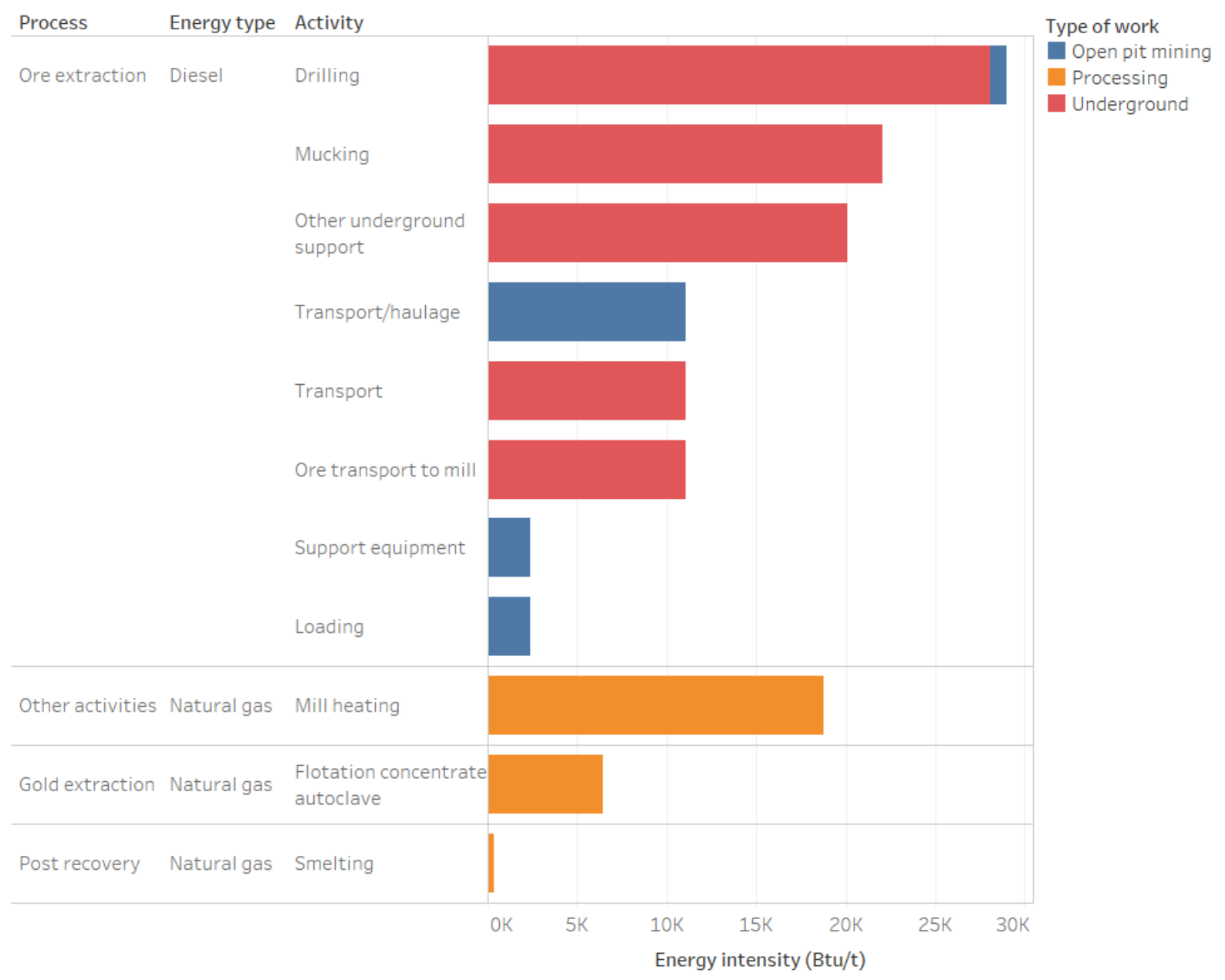

Figure 15. Fossil fuel use in gold production

Data sources: Katta, Davis, and Kumar 2020, as compiled from several sources such as Natural Resources Canada, U.S. Department of Energy and other studies

As mentioned earlier, current commercially available renewable technologies may not be able to economically substitute for the use of natural gas in high temperature processes at the moment but may be able to do so under the right conditions in the future. 


\section{Challenges for Renewable Integration in Mining Operations}

Despite renewable potential, as presented in Section 4, the ratio of renewable to total energy used in the mining industry is still small (BNEF 2019). On November 7, 2019, Joint Institute for Strategic Energy Analysis (JISEA) hosted a workshop with mining industry professionals and related stakeholders to discuss the opportunities for and barriers to deployment of renewable energy technologies on mine sites. The workshop was followed by phone calls with select mining companies to further discuss challenges and opportunities. Some of the key challenges elicited from these conversations are presented in this section with potential solutions identified in Section 8.

\subsection{Conflicting Business Models}

Principal among the challenges discussed was the misalignment in commercial incentives between the mining and energy industries. Because of cycles in commodity prices, the mining industry values flexibility, or the ability to ramp down or cease production at a mine site if the metal market price becomes unprofitable to keep the mine open. However, of the high capital costs for renewable energy, renewable energy power purchase agreements (PPAs) typically longer term in nature.

Mine life and renewable asset life can also be misaligned. As mentioned in Section 4.4, most mining projects evaluate profitability of the mine project to the end of their estimated life (which can range from 2 to more 50 years), while renewable project payoffs might be a minimum of 8 years. This mismatch in asset life makes negotiating cost-effective renewable energy contracts difficult. Many renewable projects associated with the mining industry are, accordingly, owned by the mining operators. However, in NREL's conversations with industry, several companies indicate that their core business is mining, not energy generation. Favorable contractual arrangements could help scale renewable integration beyond what mining companies can install and manage by themselves. Also, some countries' host policies do not support favorable business models for renewable integration in that they lack the legal framework for net metering policies to export excess energy to the grid, or for renewable project ownership transfers post-mining.

\subsection{Need for Technology Proofs of Concept}

The growing renewable energy industry has largely been focused on electricity production and grid integration over the last decade, and technology solutions designed for other industrial processes are still nascent. While wind, solar and other renewable technologies have established solid track records, there is limited experience in their integration into on-grid and off-grid mining sectors. Other energy service technologies, such as the expanding energy storage and advanced control markets, are becoming more common within the utility sector; however, the associated technical and financial models are still largely untested within the mining industry. Other truly emerging technologies such as hydrogen mobility and fuel cells for power production and resiliency have limited commercial histories. For off-grid mines, which likely have some of the highest potential for renewable energy deployments due to the traditionally high cost of energy services, incorporating larger contributions of variable renewable technology, while demonstrated in other smaller commercial and utility applications, have not been widely demonstrated at scale within the mining sector. While a few larger companies have run pilots to 
demonstrate these technologies for industry, they remain out of reach for mid-market and smallscale mining operators without analytic and financial support.

\subsection{Lack of Renewable Energy Awareness and Expertise}

Decision makers in both the private sector and within some governments do not often consider renewable solutions during mine planning, negotiation, and design. Most stakeholders at the workshop indicated that the engineers that conduct feasibility studies to determine a mine's design are unequipped with the skill sets and detailed information to incorporate renewable energy into their analyses. Governments and regulators in many countries where mining comprises an appreciable portion of GDP also do not have experience in incorporating renewables into their power system, again limiting the abilities of mines to access renewable energy though power purchase contracts. Mining policies, development agreements, evaluation tools, and energy policies in mining countries are generally not created with renewable energy in mind. Additionally, fossil subsidies, special tax conditions and fuel levy exemptions granted to mines through mining agreements can inhibit the use of alternative energy sources.

\subsection{Land Constraints}

Another impediment that the mining industry faces is the availability of land on which to site renewable energy assets. Mining companies at the workshop pointed to a general misconception about the footprint of mine sites, and how little of the terrain is of suitable grade and ground cover for solar PV or wind turbine installation. Also, suitable land for renewable projects could be the same land that has mineral potential (i.e., to host mineral resources and reserves or have significant exploration potential). 


\section{Enabling Approaches}

JISEA's conversations with mining stakeholders revealed a pervasive and growing interest in renewable integration within the mining industry. This section presents enabling approaches that could help with scaling this integration.

\subsection{Alignment of Business Model and Incentives}

Some mining companies are currently executing PPAs with renewable projects, and have selffinanced, regardless of the challenges with mismatched commercial incentives. However, many mining companies, especially small- to medium-size operations, are still wary of the lack of flexibility renewable energy options present, and/or lack the funding needed for initial investment. Policy support will be key in developing contract structures (PPAs) that better align incentives and regulatory frameworks that support net metering for grid-connected mining operations. Conducting analysis of costs and benefits of integrating renewables to pilot mining sites could be used to inform respective governments and other key stakeholders, such as the financial sector, which provide funding to these projects. The task to engage the energy and mining industries in developing these suitable PPAs can be facilitated by host governments that have the most to gain in terms of stimulating local economies, increasing tax revenues, and achieving GHG emissions goals, among other benefits.

\subsection{Capacity Building}

As discussed in Section 4, there are several technical considerations for integrating renewable sources into mining operations, many of which will need to be tailored to specific mine needs. Access to existing tools, tool integration, and training to use appropriate tools to assess renewable integration potentials during a pre-feasibility phase will be important to expand renewable energy development, especially for small- to medium-size companies and the consulting engineering companies that they use to conduct mine development. These capabilities can also be provided through renewable energy developers, third-party independent engineers or research institutions. Additionally, education programs at colleges and universities, and within professional certification organizations, should be used as means of addressing this knowledge gap.

\subsection{Research and Development}

More $R \& D$ is required to incrementally advance past today's barriers to integrating renewables into mining operations. The mining industry needs cost-effective solutions for scaling renewable use, or for using renewable sources to produce high-temperature heat, or for low-cost energy storage with longer durations. There are also R\&D opportunities for other emerging solutions such as green hydrogen production as alternative low-emissions feedstocks or for heating. Similarly, there are opportunities to electrify transportation (for equipment that is currently powered by diesel) and to improve the energy efficiency of material haulage (e.g., energy recovery on downhill transportation). $R \& D$ investments for the mining industry can have second-order benefits in terms of advancing solutions for other energy-intensive industries, including chemicals and food processing. Progress has been made within the utility sector to incorporate large amounts of renewable energy while expanding general electrification of the energy sector. The mining industry does not need to lead the efforts in renewable energy 
adoption but can realize significant gains in renewable energy use by using technology and techniques that have been deployed in other sectors.

\subsection{Pooling Resources}

The availability of capital is one of the major roadblocks to scaling renewables in places where favorable PPAs may not be available. Many mining activities are located in close proximity to other producers (e.g., processing facilities) and local communities. Pooling resources between these parties can allow for the installation of a shared system that serves local energy needs. This could be a viable solution, especially for small- to medium-scale mine sites with limited capital availability.

Especially for off-grid or edge-of-grid applications, there is an expanded opportunity to employ multi-technology microgrid systems, which can confer resiliency benefit. ${ }^{13}$ Mining companies already invest internationally, such as in operations in Sub Saharan Africa, and to an IPP or grid (World Bank 2014); the same investment model could be used to acquire a multi-technology microgrid that can shared. A mine site could act as an anchor customer to such a microgrid and local communities could benefit from an additional, reliable source of energy (provided that the community and mine site are in close enough proximity to minimize wiring costs). Policy and regulations are often key in facilitating microgrids, so this is another area where engagement with governments can be critical.

\subsection{Government Policies and Regulations}

As with microgrids, government policies and regulations are central to many of the enabling approaches discussed in this report. At a global level, there is increasing coordination and cooperation to deploy renewable energy technologies, but these efforts can be stalled in the implementation at the county- and local-level. As mentioned previously, in most resource rich countries, existing policies and regulations were not created with renewable sources in mind. It is only recently that some of these countries have begun reviewing their policies and regulations to help scale the development of renewable resources, but often these do not explicitly contemplate the mining industry.

Additionally, in many developing countries, local content policies around the mining sector require companies to source a certain percentage of intermediate goods from domestic manufacturers (Stephenson 2013). Manufacturing is an energy-intensive sector, and many of these developing countries have low access to energy, and or have unreliable energy generation. Renewable energy could be used to support low energy intensive manufacturing such as agribusiness and could offer countries opportunities to reap benefits of their local contact benefits and mining companies to fulfill their local content requirements. The collaborative efforts between the mining industry, energy industry, international organization, and host governments will be needed to create supportive policy and regulation support to scaling renewables. For example, large systems could be installed that can be shared between miners and communities; this kind of investment will require clear mechanism supported by policy and regulations.

\footnotetext{
${ }^{13}$ There are, however, notable challenges with productive uses for microgrids in remote communities. See Booth et
} al. (2018). 
To assist mines specifically in accessing renewables, governments may need to review their tax exemptions and subsidies that currently apply to fossil fuel purchases or explore the possibility for carbon pricing or renewable energy portfolio standards (which can create tradable renewable energy certificates). Research and documentation of mechanisms by which governments have traditionally had a high impact on their renewable energy policy goals and how they would apply to renewable energy would also be useful. For example, government policies can help in innovating green hydrogen technologies, stimulating commercial demand, building infrastructure, and reducing cost through funding, among other actions (IEA 2019). 


\section{Conclusion}

Mining is both an energy-intensive industry and a major source of raw materials for other industries, including renewable energy technologies. As a major contributor to global GHG emissions, largely due to its energy intensity, the mining industry should realize that the demand for raw materials will increase as many low-income economies shift to middle-income status; and the pressure in the mining industry to reduce emission from their operations will intensify. Because mining operations are so energy intensive, they are also quite sensitive to energy costs and energy cost variability. The rapidly lowering costs of wind and solar PV technologies provide strong financial incentives to expand the use of renewable energy within the mining industry. Many options are available to the mining sector to reduce carbon production and take advantage of energy cost savings, such as an increase in energy efficiency measures, expanded use of energy recovery, and the use of renewable energy to supply electric, transportation and thermal energy needs. These clean-energy options are not without challenges and remain mostly unused across the mining sector. This report explored the challenges, opportunities, and enabling approaches for renewable use in mining operations.

The viability of different energy sourcing options depends on where the mine is and whether it receives power from an external source or by self-generation. Additionally, what phase the mining project is in - whether development, construction or operation phases will also have a major impact on the viability of incorporating different renewable options.

Renewable energy can be integrated into the extraction, processing, and refining activities of mineral production. These activities include, but are not limited to, transportation, drilling, digging, loading, and power generation for mine sites without grid connection. For mines that are grid-connected, working with the utility to expand the use of renewable energy either on the utility or mine side of the utility meter could provide many of the primary benefits of renewable energy (e.g., lower costs and reduced GHG emissions) while potentially sheltering the mines from some of the more complicated legal and financial concerns of developing their own renewable energy sources. Renewable energy can also be used to provide process heat, though most current sources are best aligned to provide low or medium value heat (i.e., below $400^{\circ} \mathrm{C}$ ).

While many mining activities are common across the mining industry, energy requirements vary. We use iron ore extraction and gold production to show different opportunities. Both commodities use a significant amount of electricity that could be decarbonized by renewable sources. Unlike gold production, iron and steel production uses a significant amount of fossil fuel as direct process feedstock or to make heat. The clean energy solution for iron and steel will require more than just using renewables if deep decarbonization is to be achieved.

Despite numerous opportunities for renewables, the mining industry has specific technical issues that will need to be considered while planning renewable development. Incorporating low contributions of renewable energy for electricity production in isolation or on the utility side of the mine meter is not technically challenging. Implementing energy efficiency efforts to transition fossil-based energy uses to electricity can also allow for expansion of renewable energy in the mining sector. Expanding the contribution of renewable energy, especially for electrically isolated mines, poses additional technical issues that may be specific to the mineral type as well as the mine, thus, will require more tailored solutions. 
Some of the major technical issues are feedstock replacement, process heat demand, and renewable energy variability. Some mining activities require fossil fuel as inputs to create either carbon or hydrogen for their processes. Some clean energy sources that can be used as feedstock are biomass and hydrogen, though the sustainable production of biomass at a scale required by the mining industry will be difficult. Some mining activities require very high-temperature process heat that is generally not currently attainable by most common renewable sources. Though current CSP, wind and solar technology can provide cost-effective thermal energy in good renewable energy resource areas above $400^{\circ} \mathrm{C}$, most high-temperature energy intensive mining activities require temperatures beyond those achieved by current commercially available CSP. The use of wind and solar energy systems for high-temperature thermal energy, although technically viable, is not currently commercial. Though variability of renewable energy is seen as a challenge to mining operations, hybrid systems can help alleviate the problem, especially when combined with energy storage and fossil-based dispatchable generation. Although it is not technical or financially viable to provide all the mines' energy needs using green sources, mines can greatly expand the use of renewable energy using commercially existing technologies.

Despite the technical and financial challenges, solutions can be employed to enable scaling of renewable in the mining industry. The first solution is alignment of a business model between the energy (utility, renewable and financing) and mining industries, which could be facilitated by host governments or other legal entities. Second, capacity building, in terms of improved tools and education programs, could be developed by technical organizations to increase the skills of key stakeholders in the mining industry. Third, greatly expanded information sharing and the development of pilot projects within the mining sector will help transfer knowledge of how renewable energy at lower energy contributions can be successfully implemented. Benefits from these experiences will also extend to other energy-intensive industries such as the chemical industry. Fourth, government policy and regulations can play an important role in implementing many of the suggested approaches in this report. For example, most basic R\&D that are far from being commercialized are pioneered with government research institutes. Additionally, government support in aligning policies across industries and advocating for integration of clean energy sources in adjacent sectors, such as the utility sector, could help both government and mining companies achieve emissions goals, which have been one of the central issues in many developing, resource-rich countries. Finally, and especially when considering longer-term deep decarbonization methods or when renewable technologies have dropped further in cost, expanded R\&D will be crucial to addressing many of the remaining technical issues to further transition the mining industry away from fossil fuels. For example, finding ways to economically achieve the high-temperature requirement with renewable sources and alternative clean and sustainable feedstock will be important to many energy intensive mining activities. Other enabling approaches include pooling of resources between the mines and the communities.

This report provides generalized insight into potential of renewable use in the mining industry. However, mining processes vary depending on a type of mineral produced and the renewable resources at the mine location. Further research could focus on identifying specific opportunities, technologies, and implementation strategies across the value chain of specific minerals or a group of minerals with similar operations procedures. Specific attention could also be placed on minerals or processes that could benefit from clean energy technologies in terms of the reduction of energy use and emissions. 


\section{References}

Alova, Galina. 2018. "Integrating Renewables in Mining: Review of Business Models and Policy Implications." OECD Development Policy Papers 14.

Andersen, Thomas Barnebeck, and Carl-Johan Dalgaard. 2013. "Power Outages and Economic Growth in Africa." Energy Economics 38: 19-23. https://doi.org/10.1016/j.eneco.2013.02.016.

ARENA (Australian Renewable Energy Agency). 2019. "Pilbara Breaks New Ground with Renewable Energy.” Media release. October 18, 2019. https://arena.gov.au/news/pilbara-breaksnew-ground-with-renewable-energy/.

BNEF. 2019. Miners Turn to Clean Energy: Costs and Key Strategies. Database.

BNEF (BloombergNEF). 2020. "Miners Begin Cleaning Up Their Act with Renewables." March 10, 2020. https://about.bnef.com/blog/miners-begin-cleaning-up-with-renewables/.

Booth, Samuel, Xiangkun Li, Ian Baring-Gould, Diana Kollanyi, Abishek Bharadwaj, and Peter Weston. 2018. Productive Use of Energy in African Micro-Grids: Technical and Business Considerations. Golden, CO: National Renewable Energy Laboratory. NREL/TP-7A40-71663. https://doi.org/10.2172/1465661.

Booth, G. Martin III, and Paul F. Bixley. 2005. "Geothermal Development in Papua New Guinea: A Country Update Report: 2000-2005.” In Proceedings World Geothermal Congress 2005, Antalya, Turkey, April 24-29, 2005. https://www.geothermalenergy.org/pdf/IGAstandard/WGC/2005/0136.pdf.

Cheng, Zhilong, Jian Yang, Lang Zhou, Yan Liu, and Qiuwang Wang. 2016. "Characteristics of Charcoal Combustion and its Effects on Iron-Ore Sintering Performance." Applied Energy Vol 161: 364-374.

Davy, Aidan. 2018. "It's Time for the Mining Industry to Step Up on the Environment and Human Rights." Reuters Events. November 28, 2018. http://www.icmm.com/en$\mathrm{gb} /$ news/2018/environment-and-human-rights.

de Moraes, Sandra Lúcia, José Renato Baptista de Lima, and Tiago Ramos Ribeiro. 2019. "Iron Ore Pelletizing Process: An Overview." In Iron Ores and Iron Oxide Materials. https://doi.org/10.5772/intechopen.73164.

de Pee, Arnout, Dickon Pinner, Occo Roelofsen, Ken Somers, Eveline Speelman, and Maaike Witteveen. 2018. Decarbonization of Industrial Sectors: The Next Frontier. McKinsey \& Company. https://www.mckinsey.com/ /media/mckinsey/business functions/sustainability/our insights/how industry can move toward a low carbon future/decarbonization-of-industrialsectors-the-next-frontier.pdf. 
Deign, Jason. 2020. Mining Giants Embrace Renewables, but Decarbonization Remains a Steep Climb.” Greentech Media. February 24, 2020

https://www.greentechmedia.com/articles/read/mining-giants-embrace-renewables-butdecarbonization-remains-a-steep-climb.

Delevingne, Lindsay, Will Glazener, Liesbet Grégoir, and Kimberly Henderson. 2020. “Climate Risk and Decarbonization: What Every Mining CEO Needs to Know.” January 28, 2020. McKinsey \& Company. https:/www.mckinsey.com/business-functions/sustainability/ourinsights/climate-risk-and-decarbonization-what-every-mining-ceo-needs-to-know.

DOE (U.S. Department of Energy). 2007. Mining Industry Energy Bandwidth Study. https://www.energy.gov/sites/prod/files/2013/11/f4/mining bandwidth.pdf.

DOE (U.S. Department of Energy. Steel Industry Profile). n.d. https://www.energy.gov/eere/amo/steel-industry-profile.

EIA (U.S. Energy Information Administration). 2020. "Electric Power Annual: Chapter 3: Table 3.1.A. Net Generation by Energy Source.” https://www.eia.gov/electricity/annual/

. 2019a. "Natural Gas Price.” https://www.eia.gov/dnav/ng/hist

—. 2019b. "Europe Brent Spot Price FOB.” https://www.eia.gov/dnav/pet/hist

- 2014. "Manufacturing Energy Consumption Survey: Energy Consumed as a Fuel by End Use.” https://www.eia.gov/consumption/manufacturing/data/2014.

EPA (U.S. Environmental Protection Agency). n.d. "Renewable Industrial Process Heat." Last updated October 26, 2017: https://www.epa.gov/rhc/renewable-industrial-process-heat.

Ericson, Sean, Jill Engel-Cox, and Doug Arent. 2019. Approaches for Integrating Renewable Energy Technologies in Oil and Gas Operations. Golden, CO: Joint Institute for Strategic Energy Analysis. NREL/TP-6A50-72842. https://doi.org/10.2172/1491378.

Guilbaud, J.S. 2016. Hybrid Renewable Systems for the Mining Industry: System costs, reliability cost, and portfolio cost risks. PhD Thesis.

https://discovery.ucl.ac.uk/id/eprint/1528681/1/FINAL\%20PhDThesis_Joel_Guilbaud.pdf

Holmberg, K., Kivikytö-Reponen, P., Härkisaari, P., Valtonen, K., \& Erdemir, A. 2017. Global Energy Consumption Due to Friction and Wear in the Mining Industry. Tribology International 115: 116-139.

IEA (International Energy Agency). 2019. The Future of Hydrogen: Seizing Today's Opportunities: Report Prepared by the IEA for the G20, Japan. International Energy Agency. https://webstore.iea.org/the-future-of-hydrogen. 
Igogo, Tsisilile, Sandor, Debra, Mayyas, Ahmad, and Jill Engel-Cox. 2019. A Supply Chain of Raw Materials Used in the Manufacturing of Light-Duty Vehicle Lithium-Ion Batteries. Golden, CO: Clean Energy Manufacturing Analysis Center. NREL/TP-6A20-73374.

https://doi.org/10.2172/1560124.

IRENA (International Renewable Energy Agency). 2015. Renewable Energy Options for the Industry Sector: Global and Regional Potential Until 2030: Background to "Renewable Energy in Manufacturing” Technology Roadmap (IRENA, 2014a). Abu Dhabi: International Renewable Energy Agency. https://www.irena.org//media/Files/IRENA/Agency/Publication/2014/Aug/IRENA_RE_Potential_for_Industry_BP 20 15.pdf.

Jackson, Christopher, and Patrick Molloy. 2018. "A Renewable Hydrogen Way Forward for the Mining Industry?” Rocky Mountain Institute. September 20, 2018. https://rmi.org/a-renewablehydrogen-way-forward-for-the-mining-industry/.

Jacob, Rhys, Martin Belusko, Ming Liu, Wasim Saman, and Frank Bruno. 2019. "Using Renewables Coupled with Thermal Energy Storage to Reduce Natural Gas Consumption in Higher Temperature Commercial/Industrial Applications.” Renewable Energy 131: 1035-1046. https://doi.org/10.1016/j.renene.2018.07.085.

Jadun, Paige, Colin McMillan, Daniel Steinberg, Matteo Muratori, Laura Vimmerstedt, and Trieu Mai. 2017. Electrification Futures Study: End-Use Electric Technology Cost and Performance Projections through 2050. Golden, CO: National Renewable Energy Laboratory. NREL/TP-6A20-70485. https://doi.org/10.2172/1416113.

Judd, Elizabeth. 2014. Raglan Mine: Canada's First Industrial-Scale Wind and Energy Storage Facility. Energy and Mines. https://energyandmines.com/wp-content/uploads/2014/08/Raglan.pdf.

Katta, Anil Kumar, Matthew Davis, and Amit Kumar. 2020. "Development of Disaggregated Energy Use and Greenhouse Gas Emission Footprints in Canada's Iron, Gold, and Potash Mining Sector." Resource, Conservation \& Recycling 152: 104485. https://doi.org/10.1016/j.resconrec.2019.104485.

Kirk, Thomas, and Charles Cannon. 2020. "Sunshine for Mines: A Brighter Vision for Sustainable Resources." Rocky Mountain Institute. January 15, 2020. https://rmi.org/sunshinefor-mines-a-brighter-vision-for-sustainable-resources/.

Langbein, Jörg. 2017. "Firewood, Smoke and Respiratory Diseases in Developing Countries: The Neglected Role of Outdoor Cooking." PLoS ONE 12(6): e0178631. https://doi.org/10.1371/journal.pone.0178631.

Larsen, Nicholas. 2019. "Favorable Renewable-Energy Economics are Now Too Attractive to Ignore.” International Banker. November 26, 2019.

https://internationalbanker.com/brokerage/favourable-renewable-energy-economics-are-nowtoo-attractive-to-ignore/. 
Lazard. 2019. "Levelized Cost of Energy and Levelized Cost of Storage 2019." Insights, November 7, 2019 https://www.lazard.com/perspective/lcoe2019.

Levesque, Michelle, Dean Millar, and Jacek Paraszczak. 2014. "Energy and Mining: The Home Truth.” Journal of Cleaner Production 84: 233-255. https://doi.org/10.1016/j.jclepro.2013.12.088.

Lezak, Stephen, Charles Cannon, and Thomas Koch Blank. 2019. Low-Carbon Metals for a Low-Carbon World: A New Energy Paradigm for Mines. Rocky Mountain Institute. https://rmi.org/wp-content/uploads/2019/12/Low-Carbon_Metals_for_a LowCarbon World.pdf.

Maennling, Nicolas and Perrine Toledano. 2018. The Renewable Power of the Mine: Accelerating Renewable Energy Integration. Columbia Center on Sustainable Investment. http://www.bmz.de/rue/includes/downloads/CCSI 2018 The Renewable Power of The Mine $\mathrm{mr}$.pdf.

Mason, Alice, Julian Luk, and Amy Hinton. 2020. "Focus: Steep Declines for LME Base Metals Prices Amid Coronavirus Pandemic; Copper Down 22\% Since Jan: Corrected." https://www.metalbulletin.com/Article/3923773/FOCUS-Steep-declines-for-LME-base-metalsprices-amid-coronavirus-pandemic-copper-down-22-since-Jan.html.

McLellan, B.C., G.D. Corder, D.P. Giurco, and K.N. Ishihara. 2012. "Renewable Energy in the Mineral Industry: A Review of Global Potential." Journal of Cleaner Production 132: 32-44. https://doi.org/10.1016/j.jclepro.2012.03.016.

MIT (Massachusetts Institute of Technology). n.d. "Strategic Metals: Will Future Supply Be Able to Meet Future Demand?"

https://web.mit.edu/12.000/www/m2016/finalwebsite/problems/supplydemand.html.

Natural Resource Canada. 2019. "Government of Canada Promotes Renewable Energy Innovation in Mining." News release. https://www.canada.ca/en/natural-resourcescanada/news/2019/01/government-of-canada-promotes-renewable-energy-innovation-inmining.html.

Norgate, Terry, and Nawshad Haque. 2012. Using Life Cycle Assessment to Evaluate some Environmental Impacts of Gold Production, Journal of Cleaner Production 29-30: 53-63. https://doi.org/10.1016/j.jclepro.2012.01.042.

Norgate, T., and N. Haque. 2010. "Energy and Greenhouse Gas Impacts of Mining and Mineral Processing Operations." Journal of Cleaner Production 18(3): 266-274. https://doi.org/10.1016/j.jclepro.2009.09.020.

Norgate, Terry, Nawshad Haque, Michael Somerville, and Sharif Jahanshahi. 2012. "Biomass as a Source of Renewable Carbon for Iron and Steelmaking." ISIJ International 52(8): 472-1481. https://doi.org/10.2355/isijinternational.52.1472. 
Norgate T.E., S. Jahanshashi, and W.J. Rankin. 2007. "Assessing the Environmental Impact of Metal Production Processes.: Journal of Cleaner Production 15(8-9): 838-848.

https://doi.org/10.1016/j.jclepro.2006.06.018.

Norton Rose Fulbright. 2017. Renewable Energy in Latin America. Norton Rose Fulbright. https://www.nortonrosefulbright.com/-/media/files/nrf/nrfweb/imported/renewable-energy-inlatin-america.pdf?la=en\&revision=66edb636-af27-43d7-8c44-c65564b1833b.

Palchack, David, Jaquelin Cochran, Ali Ehlen, Brendan McBennett, Michael Milligan, Ilya Chernyakhovskiy, Ranjit Deshmukh, Nikit Abhyankar, Sushil Kumar Soonee, S.R. Narasimhan, Mohit Joshi, and Priya Sreedharan. 2017. Greening the Grid: Pathways to Integrate 175 Gigawatts of Renewable Energy into India's Electric Grid, Vol. I: National Study. Greening the Grid Program. https://www.nrel.gov/docs/fy17osti/68530.pdf .

Sahu, H., B, N. Prakash, and S. Jayanthu. 2015. "Underground Mining for Meeting Environmental Concerns: A Strategic Approach for Sustainable Mining in Future." Procedia Earth and Planetary Science 11: 232-241. https://doi.org/10.1016/j.proeps.2015.06.030.

Sell, Christopher. 2020. "How the Pandemic Wiped Out Oil Demand Around the World." Bloomberg Green. April 9, 2020. https:/www.bloomberg.com/news/articles/2020-04-09/howthe-pandemic-wiped-out-oil-demand-around-the-world.

Slavin, A. 2016. "First Solar PV and Battery Plant to be Built in Australia, BHP Partners Up." Energy and Mines. https://energyandmines.com/2016/09/first-solar-pv-and-battery-plant-to-bebuild-in-australia-bhp-partners-up/.

Spector, Julian. 2019. "CSP Startup Heliogen Cranks Up Solar Thermal to 1,000 Degrees." Greentech Media. November 19, 2019. https://www.greentechmedia.com/articles/read/heliogencranks-solar-thermal-up-to-1000-degrees-cel.

Spence, Andrew. 2020. "New \$1 Billion Mine Looks to Solar, Wind, Batteries for 80\% of Power Needs.” RenewEconomy. February 13, 2020 . https://reneweconomy.com.au/new-1-billionmine-looks-to-solar-wind-batteries-for-80-of-power-needs-90179/.

Statista. 2020. "Duration of the Extraction Period of a Mine by Selected Commodities. Statista Research Department. March 19, 2013. https://www.statista.com/statistics/255479/mine-life-percommodity.

Stephenson, Sherry. 2013. Addressing Local Content Requirements: Current Challenges and Future Opportunities. Geneva: International Centre for Trade and Sustainable Development. https://pdfs.semanticscholar.org/8d6e/3864668d88c93f1218eab0c1174b5436e64e.pdf.

University of Australia. 2019. "Renewable Energy Solution for Industrial Heat Applications." March 14, 2019. https://phys.org/news/2019-03-renewable-energy-solution-industrialapplications.html.

World Bank. 2014. Africa: Power Mining Projects Database. https://datacatalog.worldbank.org/dataset/africa-powermining-projects-database-2014. 
World Mining Data. n.d. "Mineral Raw Materials." World Mining Data. https://www.worldmining-data.info/?World_Mining_Data_Mineral_Raw_Materials.

World Steel Association. 2019a. World Steel in Figures 2019. World Steel Association. https://www.worldsteel.org/en/dam/jcr:96d7a585-e6b2-4d63-b943-

4cd9ab621a91/World\%2520Steel\%2520in\%2520Figures\%25202019.pdf.

- 2019b. Steel and Raw Materials: Factsheet. World Steel Association.

https://www.worldsteel.org/en/dam/jcr:16ad9bcd-dbf5-449f-b42c-

b220952767bf/fact_raw\%2520materials_2019.pdf.

Zakharia, Nickolas. 2020. "Mining Heavyweights Form Green Hydrogen Consortium." Australian Mining. March 19, 2020. https://www.australianmining.com.au/news/miningheavyweights-form-green-hydrogen-consortium/. 


\section{Appendix}

\section{A.1 Global Production of Mined Materials in 2017}

Table A-1 represents Top global production of mined materials in 2017, except aggregates which covers the United States only. For the metal group, Iron and steel is produced in large quantities followed by Bauxite and aluminum.

Table A-1. Global Production of Mined Materials, 2017

\begin{tabular}{|c|c|c|c|}
\hline Material Group & Commodity & & Production \\
\hline Iron and & Iron & $2,430,000,000$ & \\
\hline ferro-alloy & Crude steel & $1,808,000,000$ & 22,840 \\
\hline metals & Manganese & $18,311,202$ & \\
\hline & Chromium & $14,586,575$ & \\
\hline & Titanium & $7,027,450$ & \\
\hline & Nickel & $2,170,374$ & \\
\hline Non-Ferrous & Aluminum & $60,536,776$ & \\
\hline Metals & Bauxite & $311,208,766$ & \\
\hline & Copper & $19,939,825$ & \\
\hline & Lead & $5,059,133$ & \\
\hline & Zinc & $12,527,486$ & \\
\hline Precious Metals & Gold & $3,339,552$ & \\
\hline & Palladium & 207,607 & \\
\hline & Platinum & 182,113 & \\
\hline & Rhodium & 22,840 & \\
\hline & Silver & $26,469,445$ & \\
\hline Industrial & Diamond(Gemstone) & $92,018,587$ & \\
\hline Minerals & Gypsum & $151,254,454$ & \\
\hline & Phosphates & $84,529,965$ & \\
\hline & Salt & $284,428,827$ & \\
\hline & Sulfur & $73,646,225$ & \\
\hline Aggregates & Construction sand and gravel(US only) & $890,000,000$ & \\
\hline & Crushed stone (US only) & $1,330,000,000$ & \\
\hline
\end{tabular}

All materials units are in metric tons except for Diamond units, which are in carats. This data source excludes global production of cements which is sometimes considered an industrial mineral. If cement were included, it would have been at the top the list of produced products. Data on global production of aggregates are not publicly available. 


\section{A.2 Metal Price Trend}

Figure A-1 provides prices of select metals from 2010 to 2018.

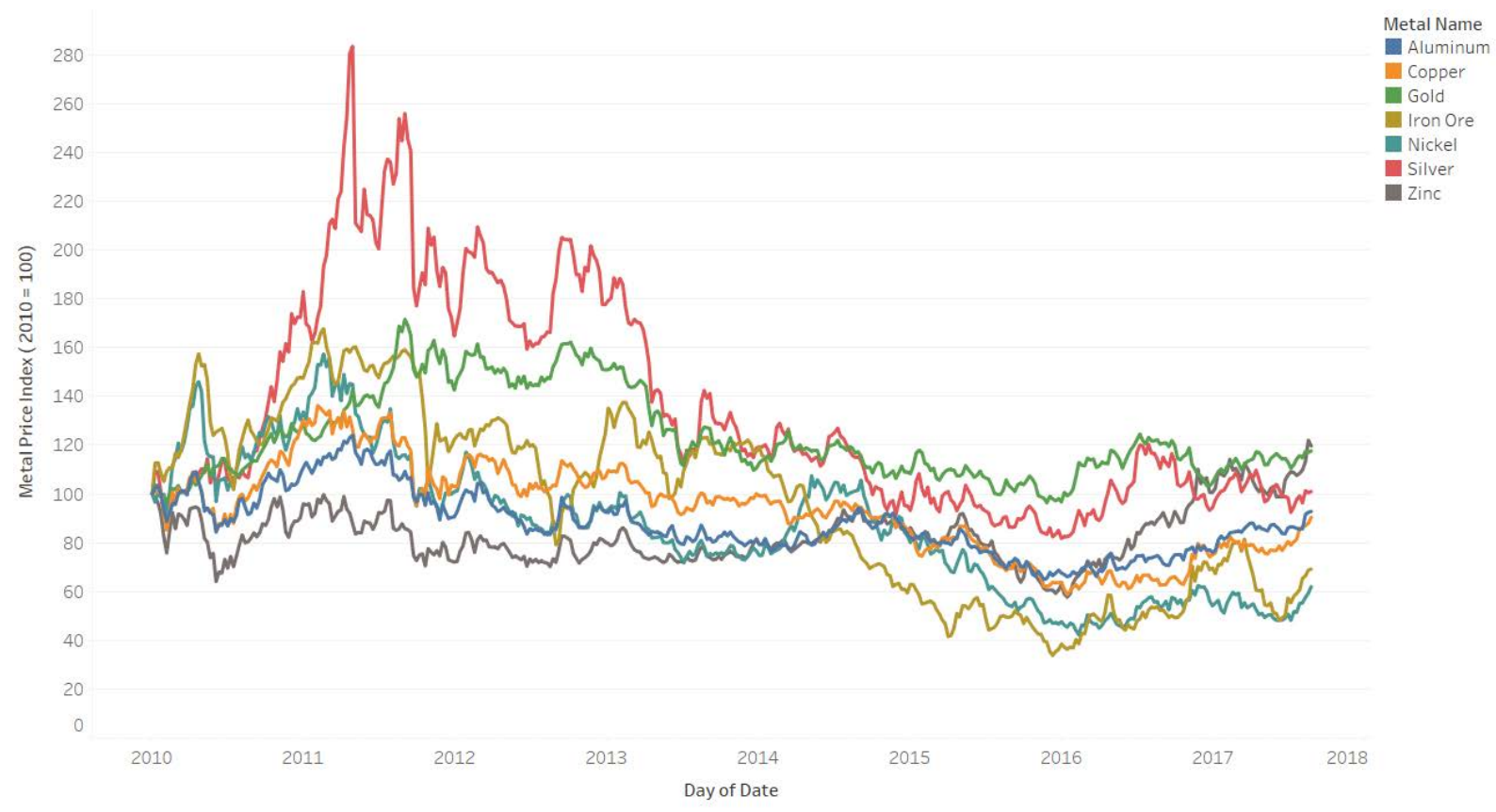

Figure A-1. Trends in metal prices

Source: BNEF 2019 